\title{
A Theory for Rapid Charging Events on the International Space Station
}

\author{
Dale C. Ferguson ${ }^{1}$, Paul D. Craven ${ }^{2}$, and Joseph I. Minow ${ }^{3}$ \\ NASA Marshall Space Flight Center, Huntsville, Alabama, 35812 \\ and \\ Kenneth H. Wright, Jr. ${ }^{4}$ \\ University of Alabama-Huntsville, Huntsville, Alabama, 35899
}

\begin{abstract}
The Floating Potential Measurement Unit (FPMU) has detected high negative amplitude rapid charging events (RCEs) on the International Space Station (ISS) at the morning terminator. These events are larger and more rapid than the ISS morning charging events first seen by the Floating Potential Probe (FPP) on ISS in 2001. In this paper, we describe a theory for the RCEs that further elucidates the nature of spacecraft charging in low Earth orbit (LEO) in a non-equilibrium situation. The model accounts for all essential aspects of the newly discovered phenomenon, and is amenable to testing on-orbit. Predictions of the model for the amplitude of the ISS RCEs for the full set of ISS solar arrays and for the coming solar cycle are given, and the results of modeling by the Environments WorkBench (EWB) are compared to the observed events to show that the phenomenon can be explained by solar array driven charging. The situation is unique because the coverglasses have not yet reached equilibrium with the surrounding plasma during the RCEs. Finally, a prescription for further use of the ISS for investigating fundamental plasma physics in LEO is given. Already, plasma and charging monitoring instruments on ISS have taught us much about spacecraft interactions with the dense LEO plasma, and we expect they will continue to yield more valuable science when the Japanese Experiment Module (JEM) is in place.
\end{abstract}

\section{Nomenclature}

$\begin{array}{ll}A_{I S S} & =\text { ISS structure exposed conducting area }\left(\mathrm{m}^{2}\right) \\ A_{S A} & =\text { solar array conducting area }\left(\mathrm{m}^{2}\right) \\ a & =1 \text { st time constant for voltage decay }\left(\mathrm{s}^{-1}\right) \\ b & =\text { 2nd time constant for voltage decay }\left(\mathrm{s}^{-1}\right) \\ C & =\text { capacitance (Farads) } \\ e & =\text { fundamental charge, electron charge } \\ \varepsilon_{0} & =\text { permittivity of free space } \\ F P M U & =\text { Floating Potential Measurement Unit } \\ F P P & =\text { Floating Potential Probe } \\ J_{e}, J_{e}, & =\text { electron current densities } \\ J_{i}, J_{i}, & =\text { ion current densities } \\ k & =\text { Boltzmann's constant }\end{array}$

${ }^{1} \mathrm{CxP}$ Environments and Constraints SIG, EM50, AIAA Senior Member.

${ }^{2}$ Space Environmental Effects Branch, EM50, AIAA Member.

${ }^{3}$ Natural Environments Branch, EV44, AIAA Senior Member.

${ }^{4}$ Center for Space Plasma and Aeronomic Research, AIAA Member. 


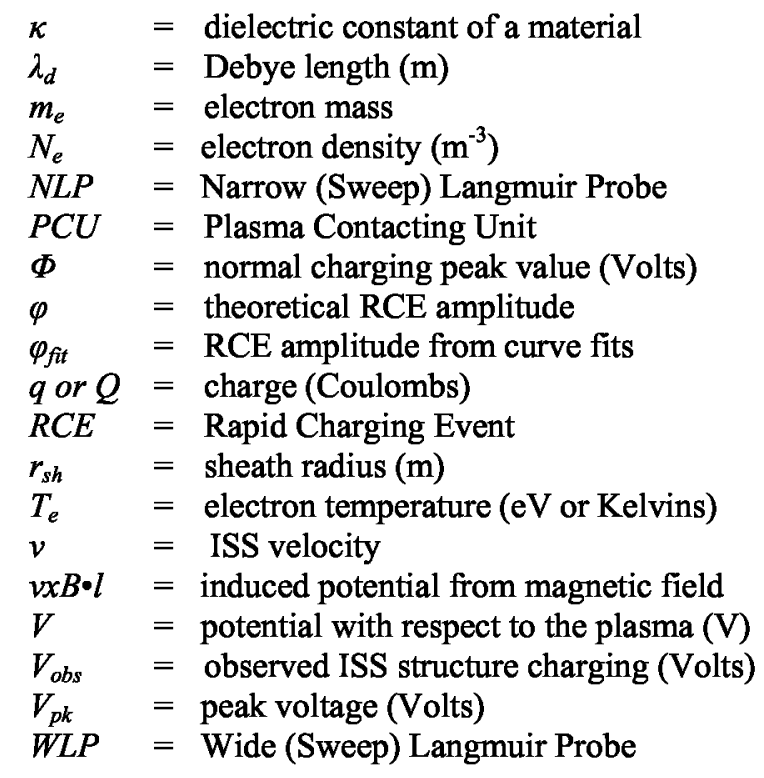

\section{History of ISS Charging Theory}

$\mathrm{T}$ HE original expectation (1991). In 1990 and 1991, a Tiger Team was convened by the Space Station Freedom (SSF) program to determine whether SSF would charge up due to its high voltage solar arrays and its negatively grounded power system. The report of the Tiger Team was that SSF would likely charge up to about $-140 \mathrm{~V}$ with respect to the plasma, that this voltage would break down its dielectric thermal control coatings, and that the potential should be actively controlled ${ }^{1,2}$. This led to the development and adoption of the PCUs (plasma contactor units) that have now been in place on ISS from the year 2000, and are still routinely used to prevent charging when EVAs are in progress.

\section{A. Revision due to electron choking (1991-1994)}

During the Tiger Team activities, it was discovered both analytically $y^{3,4}$ and experimentally (through ground tests in plasma chambers ${ }^{5}$ ) that electron collection on the ISS solar cells is effectively choked off by the potentials on the coverglass surfaces and in the gaps between solar cells for electron temperatures above about $0.5 \mathrm{eV}$, and for fully neutralized coverglass surfaces. For electron temperatures less than that, electron collection (and the amount of ISS charging) would increase strongly with decreasing electron temperature.

\section{SAMPIE vs. PASP+}

Two flight experiments were performed in 1993 and 1994. The Solar Array Module Plasma Interactions Experiment (SAMPIE), a flight experiment conducted on the Space Shuttle, used ISS-type solar cells cemented to a solid substrate, and seemed to show that electron choking would be very effective at electron temperatures of about $0.2 \mathrm{eV}^{6}$. The other experiment, Photovoltaic Array Space Power - Plus (PASP+), performed on a Pegasus-launched satellite with ISS-type cells on a spring-loaded flexible substrate, seemed to show that electron choking was not nearly as effective as SAMPIE had implied ${ }^{7}$. Ground tests ${ }^{8}$ were interpreted as indicating that the flexible substrate tests would be more representative of collection on the real ISS arrays, so models were adjusted to simulate PASP+ like collection for ISS arrays. After the FPP was installed on ISS in 2000, models were re-adjusted back to agree with the SAMPIE results, as no agreement with the measured charging could be obtained with the PASP+ values.

\section{B. Revision due to extra ion collection $(2002,2006)$}

Post-2000 models also could only be made to fit the FPP observations if two more sources of ion collection were included. These were ion collection from the (grounded) solar array mast wires and another mysterious conducting area probably located on the Russian segment ${ }^{34,35,36}$. 


\section{Russian blanket testing}

In order to determine the ion collection on the Russian segments, samples of Russian thermal blankets were tested in plasma chambers at the Marshall Space Flight Center'. It was found that due to conducting material incorporated in the blankets, some 20-35 square meters of ion collecting area existed on the Russian segment, and this would also lead to smaller than expected charging. Incorporating both of these ion collection areas led to very good agreement of physical models with the FPP-observed charging values ${ }^{36}$.

\section{Application to "normal" charging}

A steady-state physical model for LEO charging called the Environments WorkBench (EWB) model ${ }^{10,37}$ was developed by Science Applications International Corporation (SAIC). A specialized version of EWB called the Plasma Interactions Model (PIM) was jointly developed by SAIC and Boeing that agreed in all essential aspects with the FPP observations. The original PIM code included electron current collection models for the solar arrays ${ }^{16}$ as well as collection on solar arrays, masts, and vehicle structure with a distribution of potential due to vxB・1 34,35,36,38 (see below).

\section{Previous Observations of Charging}

\section{A. The original FPP - capabilities and limitations}

The original Floating Potential Probe (FPP) was placed into service on ISS in December, 2000. It had two probes, a Langmuir probe to determine plasma characteristics and the structure potential if less than about 10 volts, and a floating potential probe to measure structure potential between 0 and $-150 \mathrm{~V}$. For structure potentials of magnitude greater than about 10 volts, no plasma data could be obtained. Although data were taken on floating potential every 0.1 second, they were analyzed in 20 second increments (the duration of a single Langmuir probe sweep). FPP operated for a period of about 4 months until April, 2001. For a full account of the original FPP, see Ferguson $^{11}$.

\section{B. "Normal" charging amounts and characteristics}

\section{Charging}

Charging as seen by FPP occurred mainly near eclipse exits, when the active side of the array was ram-facing, before most solar array strings had been turned off for power management, and when the plasma temperature was still low. Ferguson and Morton ${ }^{12}$ showed that the normal charging lasted for several minutes after eclipse exit and could be described in terms of plasma parameters by the equation:

$$
\Phi=-2.6907 \mathrm{~N}_{\mathrm{e}}^{0.1057} \mathrm{e}^{-8.02 \mathrm{Te}}
$$

where $\mathrm{N}_{\mathrm{e}}$ is the electron density and $\mathrm{T}_{\mathrm{e}}$ is the electron temperature at eclipse exit. The steep dependence of this charging on electron temperature is reflective of the electron-choking effect mentioned earlier.

For the single solar array in place when FPP was operational, no charging of magnitude above about 30 volts was observed, and the charging peaks typically lasted for a few minutes after eclipse exit. Ferguson and Gardner ${ }^{13,14}$ extrapolated the charging to a fully array-populated ISS and found that normal charging in excess of 80 volts could occur.

\section{2. vxB・1}

The electric field induced by the ISS motion through the ambient magnetic field, the vxB・l effect, can be important. At its maximum value, it can produce a difference of about $0.3 \mathrm{volts} / \mathrm{m}$ in potential along a truss member. For a 100 meter long truss on ISS, vxB・1 can induce up to a $30 \mathrm{~V}$ difference in local potentials relative to the plasma potential ${ }^{15}$. This effect was quite well modeled by PIM (see for example Mandell et al. ${ }^{16}$ ), and can lead 
to locally heightened or lessened ion or electron current collection. In what follows, we will take out this effect when necessary, and will deal only with potentials due to the difference in electron and ion collection of the ISS solar arrays and structure.

\section{FPMU}

\section{A. Description}

The FPMU is a package of four plasma instruments designed and built by Utah State University (USU) under contract to the NASA/Johnson Space Center (JSC). The purpose of the FPMU is to measure the local potential of the ISS relative to the plasma and to measure the density and electron temperature of the local plasma. The four probes are: a Floating Potential Probe (FPP), a Plasma Impedance Probe (PIP), a Wide-sweep Langmuir Probe (WLP), and a Narrow-sweep Langmuir Probe (NLP) with associated electronics. The operation is autonomous, with either an on or an off state. The FPMU has been described elsewhere [Swenson et al. ${ }^{27,28,29}$, Wright et al. ${ }^{25}$ ] but a brief description of each probe is given below. Initial FPMU on-orbit results are given in Wright et al. ${ }^{25}$, Barjatya et al. $^{33}$, and Coffey et al. ${ }^{26}$.

\section{Floating Potential Probe (FPP)}

The FPP is a gold-plated sphere of radius $5.08 \mathrm{~cm}$ and is essentially a high impedance $\left(\sim 10^{11} \Omega\right)$ voltmeter with the other connection referenced to ISS ground. The sphere potential is determined by local plasma conditions, and within a few $\mathrm{kT}_{\mathrm{e}}$ of the plasma potential, provides a reference for measuring the potential of the ISS $(\mathrm{k}=$ Boltzmann's constant). Data is sampled at $128 \mathrm{~Hz}$ with $100 \mathrm{mV}$ resolution. This is the primary probe for ISS floating potential because it is a direct measurement of the floating potential.

\section{Wide-Sweep Langmuir Probe (WLP)}

The WLP is a gold-plated sphere also of radius $5.08 \mathrm{~cm}$. The voltage applied to the probe is swept from $-20 \mathrm{~V}$ to $+80 \mathrm{~V}$ relative to chassis ground (ISS structure) and the resulting currents to the probe are measured. Sweeps are accomplished each second, with the potential sweeping from low to high voltage in one second and back down from high to low in the next second. The sweep is comprised of three parts as described by Wright et al. ${ }^{25}[2008]$ and references therein. Step sizes of $\sim 25 \mathrm{mV}$ from $0 \mathrm{~V}$ to $50 \mathrm{~V}$ provide sufficient resolution for a determination of $\mathrm{T}_{e}$ (which requires several samples in the electron retarding portion of the sweep). The floating potential can be obtained over the full $-20 \mathrm{~V}$ to $+80 \mathrm{~V}$ range, within an uncertainty of $+/-2 \mathrm{~V}$. The WLP is the primary probe for densities because its wide voltage sweep allows complete coverage of the ion and electron saturation regions over a wide range in floating potential. Plasma temperatures derived from the WLP are considered secondary to those derived from the NLP described below.

\section{Narrow-Sweep Langmuir Probe (NLP)}

The NLP is a guarded gold-plated cylinder with collector dimension of radius $1.43 \mathrm{~cm}$ and length $5.08 \mathrm{~cm}$. The NLP is placed mid-way on the boom supporting the FPP. A sweep from $-4.9 \mathrm{~V}$ to $+4.9 \mathrm{~V}$, in steps of $\sim 12 \mathrm{mV}$, is applied to the NLP during one second, followed by a sweep down from $4.9 \mathrm{~V}$ to $-4.9 \mathrm{~V}$ in the next second. This sweep voltage is referenced to the floating potential measured by the FPP. In this way, the electron and ion saturation regions of the plasma current-voltage profile are seen, as the region sampled will move through the $-180 \mathrm{~V}$ to $+180 \mathrm{~V}$ range of the FPP. This configuration allows the density and electron temperature to be determined at $1 \mathrm{~Hz}$. Electron temperature derived from this probe is considered as the definitive temperature relative to that derived from the WLP because of the smaller step size and because of a suspected change to the work function of the WLP sphere surface. During rapid changes in floating potential, the plasma potential may be outside of the sweep range of the NLP, and in this case, no NLP plasma temperature can be obtained. 


\section{Plasma Impedance Probe (PIP)}

The PIP consists of a short dipole antenna electrically isolated from the ISS. The PIP measures the electrical impedance (magnitude and phase) of the antenna at 256 frequencies ranging from $100 \mathrm{KHz}$ to $20 \mathrm{MHz}$ in one second. Electron density, electron-neutral collision frequency, and magnetic field strength can potentially be deduced from these impedance measurements.

\section{B. Enhanced Capabilities}

In addition to having more instruments and more redundancy than the original FPP, FPMU has greatly improved time resolution. Rather than 20 second time resolution on floating potential measurements (in the original FPP analysis), FPMU has $128 \mathrm{~Hz}$ resolution on floating potential. It was this enhanced time resolution that enabled FPMU to detect the rapid charging events that are the focus of this paper.

\section{Discovery of RCEs}

Craven et al. ${ }^{19}$ provide a survey of the different types of charging events observed by the FPMU. The normal charging events previously observed by the original FPP are also seen by the FPMU at every eclipse exit when the PCUs are not in operation. A new type of event, also described by Craven et al. ${ }^{19}$, was dubbed the Rapid Charging Event (RCE). The distinguishing characteristic of RCEs, compared to more normal charging events, is the very rapid ( $<10$ seconds) rise time for the charging, which could not have been detected by the original FPP. Typically, RCEs only last for less than 30 seconds, and have a faster rise time than decay time. A typical RCE is shown in Figure 1 below. The charging is negative, but in the rest of the paper we will refer to its amplitude as a positive number.

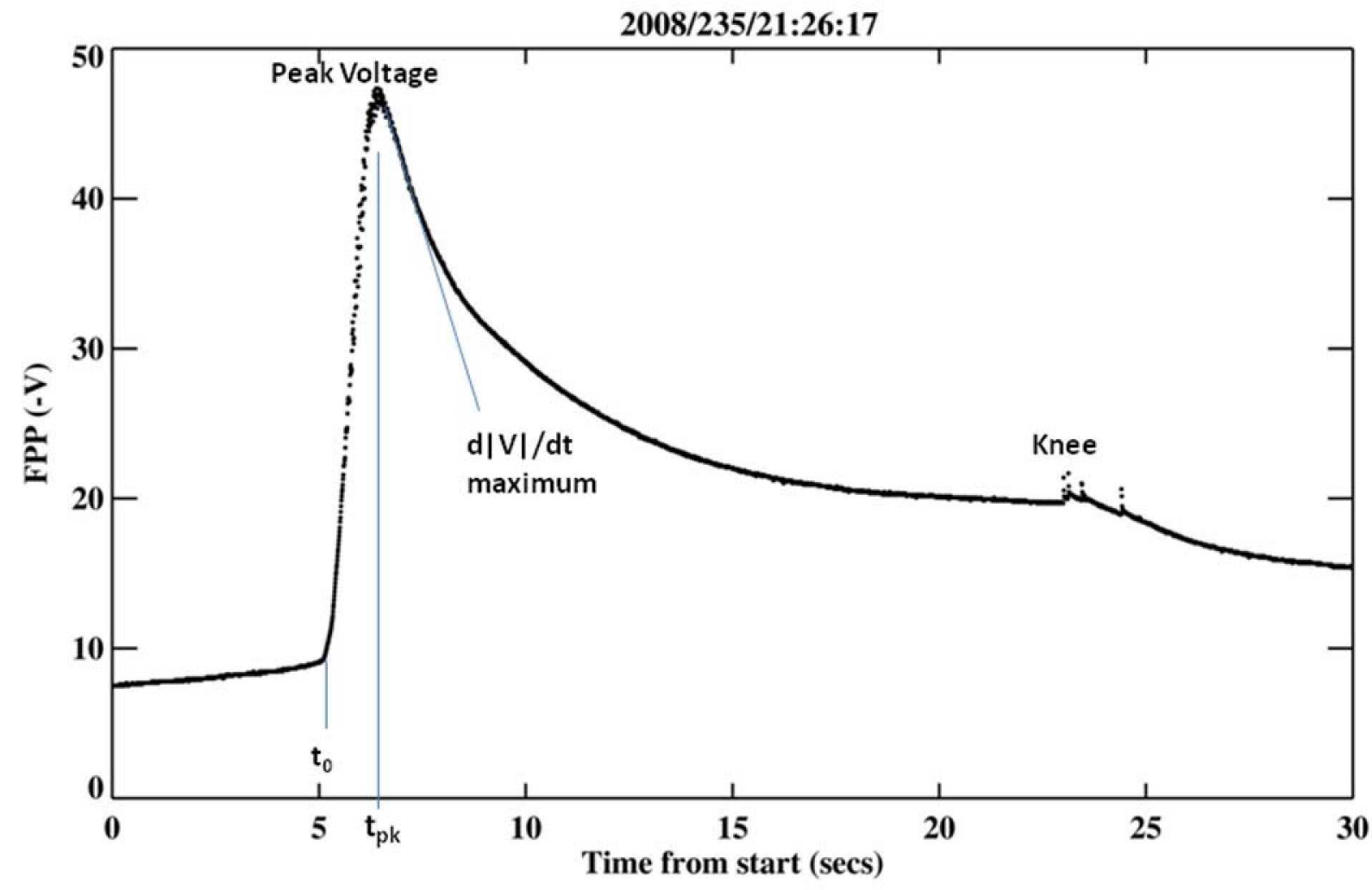

Figure 1. A typical RCE at $128 \mathrm{~Hz}$ time resolution. Some characteristics are labeled.

In addition to the rapid onset of charging, it is mentioned in Craven et al. ${ }^{19}$ that RCEs have a knee in their voltage decay profile several seconds after their onset. Examination of the ISS power system telemetry has provided the 
explanation for this knee. It is ISS power system power management, which starts shunting strings automatically within 10 seconds after the onset of current from the arrays at eclipse exit. It is expected that as power demands on the arrays go up with time, this shunting will be less common, and the knee may become less prominent.

In addition, Craven et al. ${ }^{19}$ mention the fact that RCEs only appear to occur for very low values of plasma density, and with one possible exception, have only been seen when ISS was coming out of eclipse. The one exception, an apparent incident at eclipse entrance, has since been discounted, as it is slower than typical RCEs and does not adhere to the typical RCE waveform. This event may be part of a separate class of charging events that occurs near the terminator. These and other examples of this type of charging event will be addressed in a later paper.

\section{A. Current balance}

\section{Rudiments of LEO Charging}

Because of the incredibly short electron response time (microseconds at most) a current balance is always maintained between ions being collected by some part of the ISS and electrons collected somewhere else. At equilibrium, the surfaces of dielectrics are at the potential where thermal electron collection is exactly balanced by ram ion collection, which is at most a few $\mathrm{kT}_{\mathrm{e}}$ away from the plasma potential. For the ionospheric plasma, with electron temperature $T_{e}$ of perhaps $0.3 \mathrm{eV}$ at most, this means that insulating surfaces should come to equilibrium at most about a volt negative of the plasma.

Of course, conductors will try to maintain a constant potential across their length, which may or may not be near the plasma potential, depending on the impressed potentials of the power system. In particular, when one has a high voltage array, such as the $160 \mathrm{~V}$ case for ISS, conductors and solar cells on one end of the sunlit array may be at the power system voltage different in potential from those on the other end. For ISS and most other satellites, the negative end of the power system is grounded to the structure, so the ISS structure may be $160 \mathrm{~V}$ negative of the most positive end of the ISS array. We call the difference of the structure potential from the plasma potential the "floating" potential of the structure. It will depend on the relative currents of electrons to the array and ions to the array and structure. Most space solar arrays tend to float about $90 \%$ negative, because the positive (electroncollecting) end of the array collects the lighter electrons about ten times as fast per unit area as the negative (ioncollecting) end of the array can collect the heavier ions.

\section{Ram Ion collection}

ISS in its orbit travels faster than the thermal velocity of the (mostly oxygen) ions it flies through. However, it is much slower than the thermal velocities of the electrons (the mesosonic condition). In general, this means that only the ram ions need be considered in current balance.

\section{a. Focusing factors (with array and structure geometrical dependences)}

A large flat conducting plate traveling through the ionosphere along its normal will collect the ram ion current density (current per unit area),

$$
J_{i}=N_{i} \vee q,
$$

where $N_{i}$ is the ion number density (usually equal to the electron number density $N_{e}$ ), $v$ is the plate velocity, and $q$ is the ion charge (usually one electron charge, e). This can also be expressed as $\mathrm{Ji}=\mathrm{N}_{\mathrm{e}} \mathrm{v}$ e. The plate rams into the ions with a speed equivalent to $4.89 \mathrm{eV}$ in energy. Because the orbital speed is much greater than the ion thermal speed, ions effectively move in straight lines with respect to the velocity vector of the plate.

A collecting conductor of radius small compared to a Debye length (see the next section below) at a negative potential $\mathrm{V}$ with respect to the plasma will see focusing of the ions. We define the current density at the surface of the collecting conductor as a primed variable. Ion focusing gives us the equation (next page): 
$\mathrm{J}_{\mathrm{i}}{ }^{\prime}=\mathrm{N}_{\mathrm{e}} \mathrm{V}$ e $\left(1+|\mathrm{V}| / \mathrm{V}_{0}\right)^{1 / 2}$, if the ions are collected by a wire perpendicular to the velocity vector, or

$$
\mathrm{J}_{\mathrm{i}}{ }^{\prime}=\mathrm{N}_{\mathrm{e}} \mathrm{v} \text { e }\left(1+|\mathrm{V}| / \mathrm{V}_{0}\right) \text {, if the ions are collected by a sphere. }
$$

See for example, Chen ${ }^{17}$. This can make ion collection much more rapid than without focusing if the ramming conductor is surrounded by space or by an insulator with surfaces at nearly the plasma potential. Surfaces in the wake will see very little ion collection because of the mesosonic condition.

\section{Thermal Electron collection}

Because the electrons are traveling much faster than the ISS, they can be collected from all angles. At first, this makes it seem like they can be effectively collected even in the wake, where the ions are excluded. In actuality, however, electrons are also excluded from the wake by the negative space charge that builds up there, so effectively, electron collection can only take place on ram or side surfaces. Where the electrons can be collected, their one-sided thermal current density per unit area is given by the equation ${ }^{32}$ :

$$
\mathrm{J}_{\mathrm{e}}=\mathrm{N}_{\mathrm{e}} \mathrm{e}\left(\mathrm{kT}_{\mathrm{e}} / 2 \pi \mathrm{m}_{\mathrm{e}}\right)^{1 / 2}=2.49 \times 10^{-16} \mathrm{~N}_{\mathrm{e}}\left(\mathrm{T}_{\mathrm{e}}\right)^{1 / 2} \text {, with } \mathrm{T}_{\mathrm{e}} \text { in Kelvins. }
$$

This is the current density that would be seen by a surface at the plasma potential. However, in actuality, three dimensional bodies in plasma are surrounded by a plasma sheath, such that if a thermal electron comes within the sheath, it must hit the surface and be collected. For surfaces near the plasma potential, the sheath envelops the surface to a distance on the order of a Debye length, given by the following equation ${ }^{31}$ :

$$
\lambda_{d}=\left(\varepsilon_{0} k T_{e} / N_{e} e^{2}\right)^{1 / 2}=7430\left[T_{e} / N_{e}\right]^{1 / 2} \text {, with } T_{e} \text { in eV. }
$$

If the surface is at some positive potential $\mathrm{V}$, the sheath will be bigger, and in the (orbit-limited) case where the sheath radius is much bigger than the radius of the collecting body, the sheath radius is given approximately by the equation $^{30}$ :

$$
\mathrm{r}_{\mathrm{sh}}=0.78\left(\mathrm{~V} / \mathrm{T}_{\mathrm{e}}\right)^{1 / 2} \lambda_{\mathrm{d}}=5.80 \times 10^{3}\left(\mathrm{~V} / \mathrm{N}_{\mathrm{e}}\right)^{1 / 2}
$$

\section{a. Sheath effects (with geometry dependence)}

Hereafter, we use Kelvins for $T_{e}$. Because all thermal electrons entering the sheath are collected, the effective electron thermal current density at the surface of the collecting body will be:

$$
\begin{gathered}
\mathrm{J}_{\mathrm{e}}{ }^{\prime}=\left(\mathrm{A}_{\mathrm{sh}} / \mathrm{A}_{\mathrm{body}}\right) \mathrm{J}_{\mathrm{e}} \text {, which for a cylindrical electron collector is } \\
\mathrm{J}_{\mathrm{e}}{ }^{\prime}=\left(\mathrm{r}_{\mathrm{sh}} / \mathrm{r}_{\mathrm{body}}\right) \mathrm{J}_{\mathrm{e}}=\left(2.49 \times 10^{-16}\right)\left(5.80 \times 10^{3}\right)\left(\mathrm{V} \mathrm{N}_{\mathrm{e}} \mathrm{T}_{\mathrm{e}}\right)^{1 / 2} / \mathrm{r}_{\mathrm{body}} \text {, or } \\
\mathrm{J}_{\mathrm{e}}{ }^{\prime}=1.45 \times 10^{-12}\left(\mathrm{~V} \mathrm{~N}_{\mathrm{e}} \mathrm{T}_{\mathrm{e}}\right)^{1 / 2} / \mathrm{r}_{\mathrm{body}}
\end{gathered}
$$

and for a spherical electron collector is:

$$
\mathrm{J}_{\mathrm{e}}{ }^{\prime}=\left(\mathrm{r}_{\mathrm{sh}} / \mathrm{r}_{\text {body }}\right)^{2} \mathrm{~J}_{\mathrm{e}}=\left(2.49 \times 10^{-16}\right)\left(3.36 \times 10^{7}\right) \mathrm{V}\left(\mathrm{T}_{\mathrm{e}}\right)^{1 / 2} / \mathrm{r}_{\text {body }}{ }^{2}
$$

\section{Charging times for dielectrics}

Most ISS conductors are covered with a dielectric material, usually for thermal reasons. The conductor underneath forms one surface of a (parallel plate) capacitor, with the other surface being the exposed surface of the dielectric. Like any capacitor, it takes a certain amount of charge to build up on this surface capacitor before the underlying electric field will be neutralized. This charge is $\mathrm{Q}=\mathrm{CV}$, where $\mathrm{V}$ is the potential of the underlying conductor, and $\mathrm{C}$ is the capacitance of the material thickness. Dividing by the area, we have $\mathrm{Q} / \mathrm{A}=\mathrm{V} \mathrm{C} / \mathrm{A}$, and when charge is collected from the plasma, $\mathrm{dQ} / \mathrm{Adt}=\mathrm{J}=\mathrm{dV} / \mathrm{dt}(\mathrm{C} / \mathrm{A})$. Thus, charge builds up so that $\mathrm{dV} / \mathrm{dt}=\mathrm{J} /(\mathrm{C} / \mathrm{A})$. For dielectric materials of uniform thickness, $C / A=\varepsilon_{0} \kappa / d$, where $d$ is the thickness of the dielectric, $\varepsilon_{0}$ is the permittivity of free space, and $\mathrm{k}$ is the dielectric constant of the material. Taking values which we will later see are relatively 
typical for the RCEs $\left(\kappa=5\right.$, a $-22 \mathrm{~V}$ charging voltage, a plasma density of $2 \times 10^{10}$ and an electron temperature of $2000 \mathrm{~K}$ ), we have for the various ISS charging surfaces the values in Table 1 below:

Table 1. Timescales for ISS charging in a plasma of $N_{e}=2 \times 10^{10}$ and $T_{e}=2000$

\begin{tabular}{|l|r|l|l|l|r|}
\hline Type of Surface & $\begin{array}{l}\mathrm{d}(\text { dielectric } \\
\text { thickness, } \mathrm{m})\end{array}$ & $\mathrm{C} / \mathrm{A}\left(\mathrm{F} / \mathrm{m}^{2}\right)$ & Type of charging & $1 / \mathrm{t}(1 / \mathrm{s})$ & $\mathrm{t}(\mathrm{sec})$ \\
\hline & & & & & \\
\hline ISS Structure type 1 & $1.30 \mathrm{E}-06$ & $3.40 \mathrm{E}-05$ & Ram Ion & $3.29 \mathrm{E}-02$ & $3.04 \mathrm{E}+01$ \\
\hline ISS Structure type 2 & $1.30 \mathrm{E}-05$ & $3.40 \mathrm{E}-06$ & Ram Ion & $3.29 \mathrm{E}-01$ & $3.04 \mathrm{E}+00$ \\
\hline ISS Solar Array & $1.50 \mathrm{E}-04$ & $2.95 \mathrm{E}-07$ & Ram Ion & $3.80 \mathrm{E}+00$ & $2.63 \mathrm{E}-01$ \\
\hline ISS Structure type 1 & $1.30 \mathrm{E}-06$ & $3.40 \mathrm{E}-05$ & Focused Ram Ion & $2.30 \mathrm{E}-01$ & $4.34 \mathrm{E}+00$ \\
\hline ISS Structure type 2 & $1.30 \mathrm{E}-05$ & $3.40 \mathrm{E}-06$ & Focused Ram Ion & $2.30 \mathrm{E}+00$ & $4.34 \mathrm{E}-01$ \\
\hline ISS beta cloth & $7.60 \mathrm{E}-04$ & $5.82 \mathrm{E}-08$ & Ram Ion & $1.92 \mathrm{E}+01$ & $5.20 \mathrm{E}-02$ \\
\hline & & & & & \\
\hline ISS CIC (cell gap) & $7.60 \mathrm{E}-05$ & $5.82 \mathrm{E}-07$ & Thermal Electron & $4.32 \mathrm{E}+00$ & $2.31 \mathrm{E}-01$ \\
\hline ISS Solar Array & $1.50 \mathrm{E}-04$ & $2.95 \mathrm{E}-07$ & Thermal Electron & $8.53 \mathrm{E}+00$ & $1.17 \mathrm{E}-01$ \\
\hline
\end{tabular}

\section{Magnetic field effects}

ISS in its orbit passes through the Earth's magnetic field. The magnetic field can constrain the lightweight electrons more easily than the heavier ions. In our initial attempt at understanding the RCEs, we ignore the effects of the magnetic field on current collection.

\section{A. Conditions for Success}

\section{Theory for RCEs}

The attributes of RCEs stated in Craven et al. ${ }^{19}$ set the criteria for a successful theory; namely, the amount of peak charging, the steep inverse dependence of the peak value on the electron density, the rapid timescale(s) for charging and charge decay, and the occurrence of RCEs only at eclipse exit.

\section{Early "sheath" charging ( $\mu$ s timescales)}

When ISS is in eclipse, and the solar arrays are not producing a distributed voltage, all surfaces of ISS are effectively negative by a few times the plasma potential, at most a volt or so. As ISS comes out of eclipse, at some insolation value the solar array voltages can switch on very suddenly, placing the positive and negative extrema of ISS about 160 volts apart. In what follows immediately, we will describe what would happen if the array turn-on time were instantaneous.

First of all, because the dielectric surfaces are capacitively coupled to the underlying conductors on short timescales, each of the solar cell coverglass surfaces will take on the same potential as the underlying cell. This means that before dielectric surface charging can take place, all surfaces will be able to collect ions or electrons as if they were conductors. In this condition, the ISS structure would float highly negative, because the solar arrays, with their much larger surface areas, would dominate the charging. And remember, if both the ion and electron collection of an array are unhindered, it will float about $90 \%$ negative. This would put the ISS structure at about $140 \mathrm{~V}$ negative at eclipse exit.

Remember, too, that the capacitance of ISS to space is very small (effectively being the capacitance of a vacuum layer the thickness of the sheath around ISS). Both ion and electron collection can charge up the sheath capacitor in less than 10 microseconds, so for an instantaneous array turn-on, ISS would charge to about $-140 \mathrm{~V}$ within 10 microseconds. This has not been observed. Observations show that the voltage turn-on time for the RCEs is about 0.1 second. Why is this?

It has been found that for an individual solar cell, the voltage turn-on time is very short (probably less than a millisecond). For a distributed array of cells, however, differences in individual cell activation insolation values 
may spread out the full array voltage turn-on time. From simple geometry of the ISS orbit and the angular diameter of the sun, one can find that the time for the array to reach full insolation is at least 8.0 seconds and can be 10 times that long. Thus, if there is a distribution in illumination for activation of individual cells of one part in 80 , it would have the effect of smearing out the other effects we mentioned above over 0.1 second, by which time other charging effects will have become important.

In what follows, we assume that the array voltage turn-on time is greater than about $1 / 10$ second (which agrees with the observed sharpness of the voltage turn-on time), so the initial very rapid structure charging (sometimes called absolute charging) does not develop. We note, also, that ram ion charging of the ISS beta cloth happens within about the first 1/10 second, so that for conductors surrounded by betacloth, ion focusing will occur from the beginning.

\section{Special initial condition (uncharged coverglasses)}

Thus, we will take as zero the time of fully developed voltage on the array, which we take to coincide with the time it takes for ion focusing to be fully developed on ISS betacloth-surrounded structure conductors. The surfaces that have not been charged to near plasma potential are the coverglass and Kapton®-covered parts of the solar arrays and all structures coated with type one and two dielectrics (anodized aluminum).

\section{a. Initial current balance equation}

Ion collection to ground will happen on exposed conductors, of which there are three main types:

i. Structural conductors surrounded by betacloth. Although the total area of conductors on ISS is estimated at 20-35 $\mathrm{m}^{2}$, it is not known what fraction is composed of small conductors where focusing will be important. Because small conducting areas are surrounded by betacloth at about the plasma potential, we assume spherical ram ion collection on the forward hemisphere only, and $\mathrm{J}_{\mathrm{i}^{\prime}}{ }^{\prime}=(1+|\mathrm{V}| / 4.89)$ $\mathrm{N}_{\mathrm{e}} \mathrm{v}$ e/ $2=1.2 \times 10^{-15}(1+|\mathrm{V}| / 4.89) \mathrm{N}_{\mathrm{e}} / 2$. At a density $\mathrm{N}_{\mathrm{e}}$ of $2 \times 10^{10}, \mathrm{~J}_{\mathrm{i}}^{\prime}=2.4 \times 10^{-5}(1+|\mathrm{V}| / 4.89) / 2$ $\mathrm{amp} / \mathrm{m}^{2}$, and if we have charging of -22 volts, say, this amounts to $8 \times 10^{-5} \mathrm{amp} / \mathrm{m}^{2}$.

Ion collection will be enhanced by photoemission on the conductor surfaces. This amounts to about $2 \mathrm{x}$ $10^{-5} \mathrm{amp} / \mathrm{m}^{2}$ in full solar ultraviolet. Not a trivial amount, it should be added to the ion collection of structure elements when in full sunlight. However, ultraviolet sunrise on ISS occurs many seconds later than infrared sunrise, which is responsible for turning on the solar array voltages. (The spectral response $^{18}$ of ISS solar cells peaks in the wavelength range of 900 to $1000 \mathrm{~nm}$, the near-infrared.) This delay can be seen in Figure 2, below.

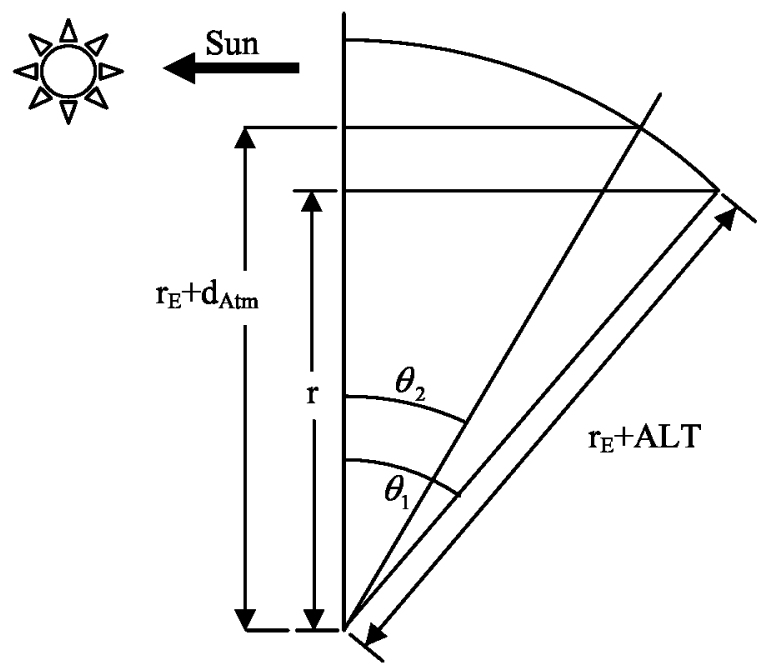

Figure 2. Geometry for atmospheric absorption. 


$$
\begin{aligned}
\cos \theta_{1} & =\frac{r_{E}}{r_{E}+A L T}, \\
\cos \theta_{2} & =\frac{r_{E}+d_{A t m}}{r_{E}+A L T},
\end{aligned}
$$

Here, we have assumed an orbital inclination of 0 degrees. For greater inclinations, the effects will be greater. The vertical line is perpendicular to the solar direction. ALT is the ISS orbital altitude. $r_{\mathrm{E}}$ is the Earth's radius. ISS first sees the sun through the entire clear atmosphere (and at infrared wavelengths) at $\theta_{1}$. For an upper limit of complete ultraviolet absorption of $d_{a t m}$, ISS first sees the ultraviolet sun at $\theta_{2}$. The orbital time between $\theta_{1}$ and $\theta_{2}$ is the time delay for the ultraviolet photoemission after the first voltage turn-on.

Putting in ALT $=350 \mathrm{~km}, \mathrm{r}_{\mathrm{E}}=6378 \mathrm{~km}$, and a conservative estimate for $\mathrm{d}_{\mathrm{atm}}$ of $30 \mathrm{~km}$ (the lowest level of the ozone layer), we find that $\theta_{2}-\theta_{1}=0.85^{\circ}$, and the time delay is about 13 seconds of time. This is beyond the peak of all RCEs treated in this paper, and so we can safely assume that photoemission by ultraviolet light is unimportant for RCEs at a clear atmosphere eclipse exit, because the ultraviolet starts reaching ISS long after the infrared emission has initiated the RCE. If the atmosphere is cloudy at the eclipse exit, the photoemission and voltage terminator may come at the same time, the relative contribution of photoemission may be greater by the amount indicated, and this would make for a lower RCE voltage peak.

For spherical collection at a cloudy eclipse exit, the local effective ion collection current density on a small conductor surrounded by an insulator is:

$$
\mathrm{J}_{\mathrm{i}}{ }^{\prime}=\left[1.2 \times 10^{-15}(1+\mid \mathrm{V} / / 4.89) \mathrm{N} / 2+2 \times 10^{-5}\right] \mathrm{A} / \mathrm{m}^{2} .
$$

For spherical collection at a clear eclipse exit,

$$
\mathrm{J}_{\mathrm{i}}{ }^{\prime}=\left[1.2 \times 10^{-15}(1+|\mathrm{V}| / 4.89) \mathrm{N} / 2\right] \mathrm{A} / \mathrm{m}^{2} .
$$

In the following, we will assume clear eclipse exits, since we are interested in the maximum amount of charging that may occur (and thus the smallest ion current density).

ii. Wires on the solar array masts. Each solar array mast has over $500 \mathrm{~m}$ of tensioning wires or rods ${ }^{42}$. Assuming a $2.38 \mathrm{~mm}$ cross-section for the wires, this gives a total collecting area of about 7.5 square meters for the 6 masts with three arrays deployed. However, geometrical factors will limit their average collection to about $1 / 2$ that of wires all oriented perpendicular to the ram. Thus, these will collect ions like cylinders, according to the equation:

$$
\mathrm{J}_{\mathrm{i}}{ }^{\prime}=\mathrm{N}_{\mathrm{e}} \mathrm{V} \text { e }\left(1+|\mathrm{V}| / \mathrm{V}_{0}\right)^{1 / 2} / 2=1.2 \times 10^{-15}(1+\mathrm{V} / 4.89)^{1 / 2} \mathrm{~N}_{\mathrm{e}} / 2
$$

iii. The edges of the solar cells on the arrays. Before the ram ions have had a chance to neutralize the array coverglasses, this will be unfocused ram ion collection, with $\mathrm{J}_{\mathrm{i}}=1.2 \times 10^{-15} \mathrm{~N}_{\mathrm{e}}$. For sake of comparison with other current densities, we can put in $\mathrm{N}_{\mathrm{e}}=2 \times 10^{10}$ to find an unfocused ram ion current density of about $2.4 \times 10^{-5}$ amps per $\mathrm{m}^{2}$, or $2.4 \mathrm{nA} / \mathrm{cm}^{2}$.

As we will see later, the electron current density on the cell edges far overwhelms that of the ions, even for focused ions, and so ion collection on the array will be unimportant. For completeness, however, we include unfocused ram ion collection on the array in the initial charging equation.

Electron collection will only occur on the solar cell edges, and will, in general, be collected from a sheath. If the coverglasses are completely un-neutralized (as at $t=0$ ), the solar cells can collect current at all of their edges. Each string on the array has 400 cells, each of which has about $0.32 \mathrm{~m}$ of cell edge 
of 6 mils uncovered thickness $=1.5 \times 10^{-4} \mathrm{~m}$, for an area per cell of $4.8 \times 10^{-5} \mathrm{~m}^{2}$ and a string edge area of $1.9 \times 10^{-2} \mathrm{~m}$. There are 82 strings per wing, and we assume four wings or two arrays, so the total edge area is $6.3 \mathrm{~m}^{2}$. When the coverglasses are completely neutralized, the electron collection will be almost completely choked off, and only the outer edges of the outermost cells will be electron collectors. This restricts the total effective edge area by a factor of 8 . Thus, the geometry of the ISS solar array is extremely important, and is taken from Kerslake and Scheimann ${ }^{18}$ and presented in Figure 3 below.

\section{Factory Verification - Wing Assembly (Typical Circuit) 400 Series Connected Solar Cells}

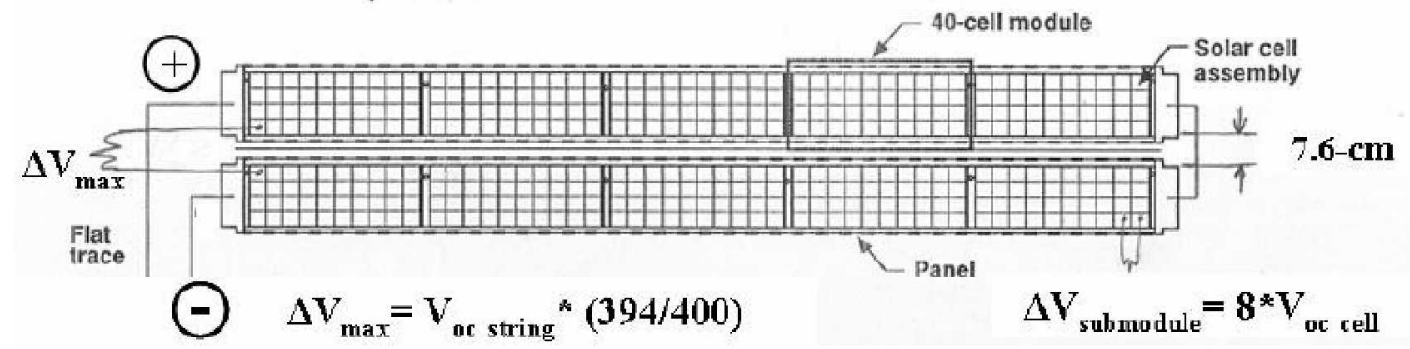

Figure 3. Geometry of the ISS Solar Array Wing Assembly.

As can be seen here, each 40 cell module (measuring about $32 \mathrm{~cm} \mathrm{x} 80 \mathrm{~cm}$ ), is connected in series with its neighbors in an across-the-u, back-the- $u$ fashion, with the legs of the $u$ separated by almost one cell width. For a structure charging value of $35 \mathrm{~V}$, one end of the sunlit array will be about $125 \mathrm{~V}$ positive, leading to a sheath radius of

$$
\mathrm{r}_{\mathrm{sh}}=5.80 \times 10^{3}\left(\mathrm{~V} / \mathrm{N}_{\mathrm{e}}\right)^{1 / 2}=0.46 \text { meters at } \mathrm{N}_{\mathrm{e}}=2 \times 10^{10}
$$

Thus, we expect the sheath, at its broadest point, to be wider than one leg (or both legs) of the $u$, and so the local sheath will be a tube shape surrounding the center of one leg of the $u$. At V $=125-80=45 \mathrm{~V}$, the turn back of the $u$ will have a sheath radius of about $0.28 \mathrm{~m}$, so the sheath diameter is still larger than the width of the $u$ leg. We feel justified in taking the electron current collection to be from a sheath that is a circular cylinder of varying radius along the array length. So, locally we have thermal current collection on the surface of a half-cylinder of radius $r_{s h}$, which then is focused onto a flat plate of width $0.32 \mathrm{~m}$. $\mathrm{J}_{\mathrm{e}}$ ' is then the ratio of these two areas, or

$$
\begin{aligned}
& \text { So, } \mathrm{J}_{\mathrm{e}}{ }^{\prime}=\mathrm{Je}_{\mathrm{sh}}(\pi / 0.32) \text {, or } \\
& \mathrm{J}_{\mathrm{e}}{ }^{\prime}=1.42 \times 10^{-11}\left(\mathrm{~V} \mathrm{~N}_{\mathrm{e}} \mathrm{T}_{\mathrm{e}}\right)^{1 / 2} \text {. }
\end{aligned}
$$

Whatever the value of the negative structure charging, which we give the value $\varphi$, the fraction of the array that is positively charged (and electron collecting) will be $(160-\varphi) / 160$ and the fraction that is negative (and ion collecting) will be $\varphi / 160$.

We are now ready to write the current balance equation. Initially,

$$
\mathrm{J}_{\mathrm{i}} \mathrm{A}_{\mathrm{SA}}(\varphi / 160)+\mathrm{J}_{\mathrm{i}}{ }^{\prime} \mathrm{A}_{\mathrm{ISS}}+\mathrm{J}_{\mathrm{i}}{ }^{\prime} \mathrm{A}_{\text {mast }}=\mathrm{J}_{\mathrm{e}}{ }^{\prime} \mathrm{A}_{\mathrm{SA}}(160-\varphi) / 160=\mathrm{J}_{\mathrm{e}}{ }^{\prime} \mathrm{A}_{\mathrm{SA}}-\mathrm{J}_{\mathrm{e}}{ }^{\prime} \mathrm{A}_{\mathrm{SA}}(\varphi / 160),
$$

where $A_{\text {mast }}$ is the mast wire area.

$$
\begin{aligned}
& A_{S A}(\varphi / 160)\left(J_{i}+J_{e}{ }^{\prime}\right)=J_{\mathrm{e}}{ }^{\prime} A_{S A}-J_{i}{ }^{\prime} A_{I S S}-J i{ }^{\prime} A_{\text {mast }} \text {, so that } \\
& \varphi=160\left[\left(J_{\mathrm{e}}{ }^{\prime} A_{S A}-J_{i} A_{I S S}-J_{i}{ }^{\prime} A_{\text {mast }}\right) /\left(J_{i}+J_{e}{ }^{\prime}\right)\right] / A_{S A} \text {, and } \\
& \varphi=160\left[J_{\mathrm{e}}{ }^{\prime} /\left(J_{i}+J_{e}{ }^{\prime}\right)\right]\left[A_{S A}-\left(J_{i}{ }^{\prime} / J_{e}\right) A_{I S S}-\left(J_{i}{ }^{\prime} / J_{e}{ }^{\prime}\right) A_{\text {mast }}\right] / A_{S A} .
\end{aligned}
$$

11

American Institute of Aeronautics and Astronautics 
Here, $\mathrm{J}_{\mathrm{e}}$ ' is the average value over the electron collecting part of an array. For all realistic cases, $\mathrm{J}_{\mathrm{e}}$ ' $>>$ $\mathrm{J}_{\mathrm{i}}$, so the charging equation becomes

$$
\varphi=160\left[1-\left(\mathrm{J}_{\mathrm{i}}{ }^{\prime} \mathrm{A}_{\mathrm{ISS}}+\mathrm{J}_{\mathrm{i}}{ }^{\prime} \mathrm{A}_{\mathrm{mast}}\right) / \mathrm{J}_{\mathrm{e}}{ }^{\prime} \mathrm{A}_{\mathrm{SA}}\right] .
$$

As a sanity check, this guarantees that for a total ion current greater than the electron current, there will be no charging.

We can calculate the average $\mathrm{J}_{\mathrm{e}}$ ' on the solar array as

$$
\mathrm{J}_{\mathrm{e}}{ }^{\prime}=1.42 \times 10^{-11}\left(\mathrm{~N}_{\mathrm{e}} \mathrm{T}_{\mathrm{e}}\right)^{1 / 2}\left(\mathrm{~V}^{1 / 2} \text { avg }\right) .
$$

Doing a numerical integration of $\mathrm{V}^{1 / 2}$, we find that $\left(\mathrm{V}^{1 / 2}\right.$ avg $) \approx(0.943)\left(\mathrm{V}_{\text {avg }}\right)^{1 / 2}$, so that

$$
\mathrm{J}_{\mathrm{e}}{ }^{\prime}=1.34 \times 10^{-11}\left(\mathrm{~N}_{\mathrm{e}} \mathrm{T}_{\mathrm{e}}\right)^{1 / 2}[(160-\varphi) / 2]^{1 / 2}=9.48 \times 10^{-12}\left(\mathrm{~N}_{\mathrm{e}} \mathrm{T}_{\mathrm{e}}\right)^{1 / 2}(160-\varphi)^{1 / 2}
$$

And finally, from (23),

$$
\begin{gathered}
\varphi / 160=\left[1-\left(\mathrm{J}_{\mathrm{i}}{ }^{\prime} \mathrm{A}_{\mathrm{ISS}}+\mathrm{J}_{\mathrm{i}}{ }^{\prime} \mathrm{A}_{\mathrm{mast}}\right) / \mathrm{J}_{\mathrm{e}}{ }^{\prime} \mathrm{A}_{\mathrm{SA}}\right], \text { so } \\
\varphi / 160=1-\left[\left(\mathrm{N}_{\mathrm{e}} / \mathrm{T}_{\mathrm{e}}\right)^{1 / 2} /\left(9.48 \times 10^{-12}\right)(160-\varphi)^{1 / 2}\right]\left[\left(\mathrm{J}_{\mathrm{i}}{ }^{\prime}\right) \mathrm{A}_{\mathrm{ISS}}+\left(\mathrm{J}_{\mathrm{i}}{ }^{\prime}\right) \mathrm{A}_{\mathrm{mast}}\right] / \mathrm{A}_{\mathrm{SA}}, \text { and } \\
\varphi / 160=1-\left[\left(\mathrm{N}_{\mathrm{e}} / \mathrm{T}_{\mathrm{e}}\right) /(160-\varphi)\right]^{1 / 2}\left[1.30 \times 10^{-4}(1+\varphi / 4.89)\left(\mathrm{A}_{\mathrm{ISS}} / 2 \mathrm{~A}_{\mathrm{sa}}\right)+1.30 \times 10^{-4}(1+\varphi / 4.89)^{1 / 2}\left(\mathrm{~A}_{\mathrm{mast}} / 2 \mathrm{~A}_{\mathrm{SA}}\right)\right] \\
\text { or, } \\
(160-\varphi) / 160=\left[\left(\mathrm{N}_{\mathrm{e}} / \mathrm{T}_{\mathrm{e}}\right) /(160-\varphi)\right]^{1 / 2}\left[1.30 \times 10^{-4}\right]\left[(1+\varphi / 4.89)\left(\mathrm{A}_{\mathrm{ISS}} / 2 \mathrm{~A}_{\mathrm{sa}}\right)+(1+\varphi / 4.89)^{1 / 2}\left(\mathrm{~A}_{\text {mast }} / 2 \mathrm{~A}_{\mathrm{SA}}\right)\right]
\end{gathered}
$$

Finally,

$$
(160-\varphi)^{3 / 2}=160\left(\mathrm{~N}_{\mathrm{e}} / \mathrm{T}_{\mathrm{e}}\right)^{1 / 2}\left[1.30 \times 10^{-4}\right]\left[(1+\varphi / 4.89)\left(\mathrm{A}_{\mathrm{ISS}} / 2 \mathrm{~A}_{\mathrm{sa}}\right)+(1+\varphi / 4.89)^{1 / 2}\left(\mathrm{~A}_{\text {mast }} / 2 \mathrm{~A}_{\mathrm{SA}}\right)\right] .
$$

Here, we can solve for $\varphi=0$ and see that there will be no charging for

$$
\left(\mathrm{N}_{\mathrm{e}} / \mathrm{T}_{\mathrm{e}}\right)^{1 / 2}>9.73 \times 10^{4}\left[2 \mathrm{~A}_{\mathrm{SA}} /\left(\mathrm{A}_{\mathrm{ISS}}+\mathrm{A}_{\text {mast }}\right)\right] .
$$

From eqn. 29, we can see that $\varphi$ depends only on the areas and $\left(\mathrm{N}_{e} / \mathrm{T}_{\mathrm{e}}\right)^{1 / 2}$, a fact that will come in handy later when we compare theory with observation.

Going forward, we will assume that for the time period we have chosen (see VI. below), with two fully functioning arrays and one not tracking, $A_{I S S}=20 \mathrm{~m}^{2}, A_{\text {mast }}=7.5 \mathrm{~m}^{2}$, and $A_{S A}=6.3 \mathrm{~m}^{2}$. With these assumptions, an excellent numerical approximation to the complicated charging equation (29) is the following :

$$
\ln \varphi=5.194-0.02415 \sqrt{ }\left[\left(\mathrm{N}_{\mathrm{e}} / \mathrm{T}_{\mathrm{e}}\right)^{1 / 2}\right]
$$

Putting in $\mathrm{N}_{\mathrm{e}}=2 \times 10^{10}$ and $\mathrm{T}_{\mathrm{e}}=2000$, typical parameters for RCEs, we solve for $\varphi=46 \mathrm{~V}$. This is similar to the charging values seen for some RCEs. We emphasize here that this number is extremely sensitive to the total conducting area of ISS as well as that of the solar arrays, and is thus uncertain by the uncertainty in those quantities.

It is important to note that the charging equation predicts a steep dependence on $\left(\mathrm{N}_{\mathrm{e}} / \mathrm{T}_{\mathrm{e}}\right)$. For instance, putting in a high value of $\mathrm{N}_{e}\left(3 \times 10^{10}\right)$ and a low value of $\mathrm{T}_{e}(1000)$ compared to typical RCEs, we find $\varphi$ 
$=30$ volts. Conversely, for $\mathrm{N}_{\mathrm{e}}=1 \times 10^{10}$ and $\mathrm{T}_{\mathrm{e}}=3000$, we find $\varphi=64$ volts. This is the behavior first noted ${ }^{19}$ for RCEs in peak voltage versus $\mathrm{N}_{\mathrm{e}}$.

As the coverglasses charge, the electrons will be focused down onto the cell gaps, and they will also charge, effectively cutting off electron collection to interior cell edges as noted above. In addition, as ions that are being focused on ISS surfaces but miss the conductors overcharge the adjacent areas, this will choke off ion collection by the structure. Thus, both electron and ion collection will decay with time. From equation (21) it is clear that it is the difference between the electron collection and the ion collection that determines the charging. At $t=0$ there is no charging, so they must be equal. After a long time has elapsed, again the charging is small, so both are equal. Since both electron and ion collection decay with time, we expect the charging curve to be a difference of two exponential decays of the same amplitude but different timescales. The $\varphi$ found above will then be the amplitude from which the two decays start out. That is,

$$
\mathrm{V}_{\mathrm{obs}}=-\varphi\left[\mathrm{e}^{-\mathrm{at}}-\mathrm{e}^{-\mathrm{bt}}\right]
$$

Here, we expect the parameter "a" to be related to the decay of ion collection, since according to Table 1, ion-collecting dielectrics on surface structures will take a longer time to charge up than will the solar array coverglasses. Thus, we expect "b" to be related to the decay of electron collection due to coverglass charging.

\section{b. Dependencies of charging amount}

- Density and Temperature dependence. According to the charging equation, the amplitude of charging should depend almost entirely on the collecting areas and $\left(\mathrm{N}_{e} / \mathrm{T}_{\mathrm{e}}\right)^{1 / 2}$.

- Time dependence. The charging peak should be the result of the difference of two exponentials as discussed above.

\section{- Amplitude versus observed amount.}

$V_{\text {obs }}=-\varphi\left[\mathrm{e}^{-a t}-\mathrm{e}^{-\mathrm{bt}}\right]$. We define the ratio $\mathrm{a} / \mathrm{b}=\mathrm{x}$. It is $\varphi$ and $\mathrm{x}$ that determine the shape of the charging peak, aside from the time as a scaling factor.

\section{- Dependence on array angle.}

Since the beta angle of the ISS orbit varies from $\sim-70^{\circ}$ to $+70^{\circ}$, a tracking array will not always be pointing directly into the ram at eclipse exit. The amount of electron collection depends on the cosine of angle the normal of the array makes with the velocity vector, so there should be a cosine dependence of $\varphi$ on array ram angle at eclipse exit.

\section{- Time of peak voltage.}

Differentiating eqn. (32) with respect to time and setting the derivative equal to zero, we find that the peak should occur at a time

$$
t_{\mathrm{pk}}=(\ln \mathrm{a}-\ln \mathrm{b}) /(\mathrm{a}-\mathrm{b})
$$

- Rate of change of voltage. $\mathrm{dV}_{\mathrm{obs}} / \mathrm{dt}=-\varphi\left[-\mathrm{ae}^{-\mathrm{at}}+\mathrm{be}^{-\mathrm{bt}}\right]$, and differentiating this with respect to time and setting it equal to zero, we find that the maximum in $\mathrm{d}\left|\mathrm{V}_{\mathrm{obs}}\right| \mathrm{dt}$ is at time

$$
\mathrm{t}=2(\ln \mathrm{a}-\ln \mathrm{b}) /(\mathrm{a}-\mathrm{b})=2 \mathrm{t}_{\mathrm{pk}} .
$$

It should be noted that there is also a maximum at a time immediately after $t=0\left(t_{0}\right.$ in Figure 1$)$. 


\section{c. Transition to "normal" charging - final current balance after coverglass charging}

"Normal" charging for ISS has electron collection severely restricted by charging of the array coverglasses, especially for electron energies above about $0.2 \mathrm{eV}$. Thus, it is in general lower than RCE charging and goes up exponentially with lower electron temperatures ${ }^{12}$. However, this will be the charging level to which the RCEs decay.

\section{RCE Observations and Comparison to Theory}

The FPMU has been operated intermittently on ISS since mid 2006. Since that time, it has amassed a fairly large statistical base of RCEs, along with ancillary data $\left(\mathrm{N}_{\mathrm{e}}, \mathrm{T}_{\mathrm{e}}\right.$, peak voltage, beta angles, etc.). In what follows, we will analyze RCEs from the period Jan. 28 through Nov. 4 of 2008. In that time period, about 80 RCEs were observed. Many of the RCEs had complex shapes in time. The difficulty in determining an all encompassing theory for them is the many variables involved that must contribute to the variety of complex shapes observed. However, there is a certain "canonical" shape that is apparent and in this paper we will concentrate on the events with that particular shape (see Figure 1). For our analysis we are using the $\mathrm{N}_{\mathrm{e}}$ and $\mathrm{T}_{\mathrm{e}}$ values averaged over a 5 second time period, just before eclipse exit. We assume that for the RCEs of simple shape, these parameters do not vary during the time extent of the RCE. We have adopted this strategy because (as was mentioned before) our best determinations of Te come from the NLP, which is unfortunately not able to keep up with the rapidly changing floating potential during an RCE. Thus, we wish to determine that a simple model can be constructed for RCEs of simple shape (where conditions are not rapidly changing). In the final analysis, a uniform sample of 42 RCEs of the simple "canonical" shape were chosen. Thus, our sample size is 42 events. In the following, the units of $\mathrm{T}_{e}$ are Kelvins.

\section{A. RCE Shapes - fits by two exponentials}

A curve fitting routine ${ }^{20}$ (TableCurve $2 \mathrm{D}$ v4.07) was used to fit various peaked functions to the RCE waveforms, using data with a time resolution of 128 values per second of time. Since the waveforms decayed down to a nonzero baseline, it was decided to fit only the first 10 to 20 seconds of the waveform, to prevent contamination from "normal" charging. In all cases, almost all of the rising voltage and a good deal of the falling voltage regions were fit. Of the 37 peaked functions available in TableCurve 2D, the so-called Intermediate Peak Function (a difference of two exponentials) gave the best fit to almost all of the RCE shapes for the 5 free parameters available (amplitude, two exponential time constants, zero offset, and zero time). All RCEs analyzed had correlation coefficients in the range from $0.895<r^{2}<0.998$. Two of the representative data fits are shown in Figures $4 \mathrm{a}$ and $4 \mathrm{~b}$. In both these plots, time in seconds is on the abscissa and negative voltage in volts is on the ordinate.

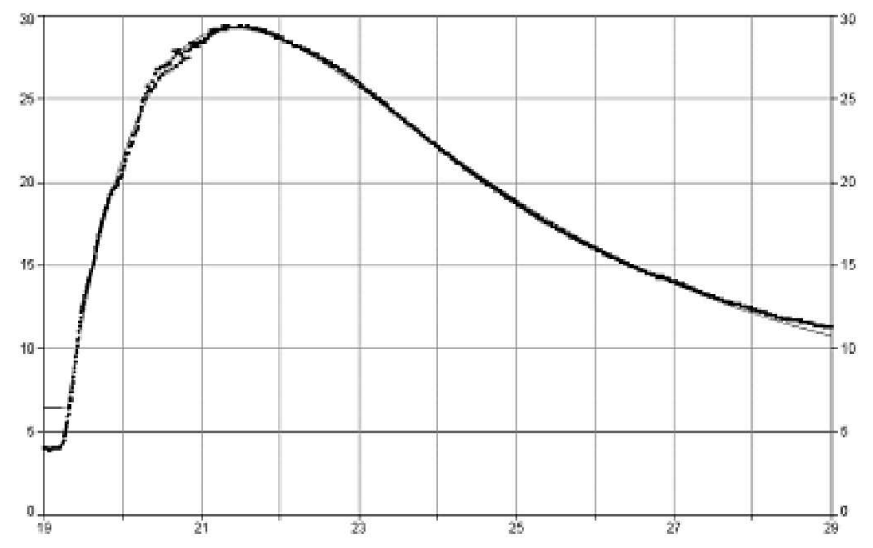

Figure 4a. A representative RCE and TableCurve fit by the difference between two exponentials. 


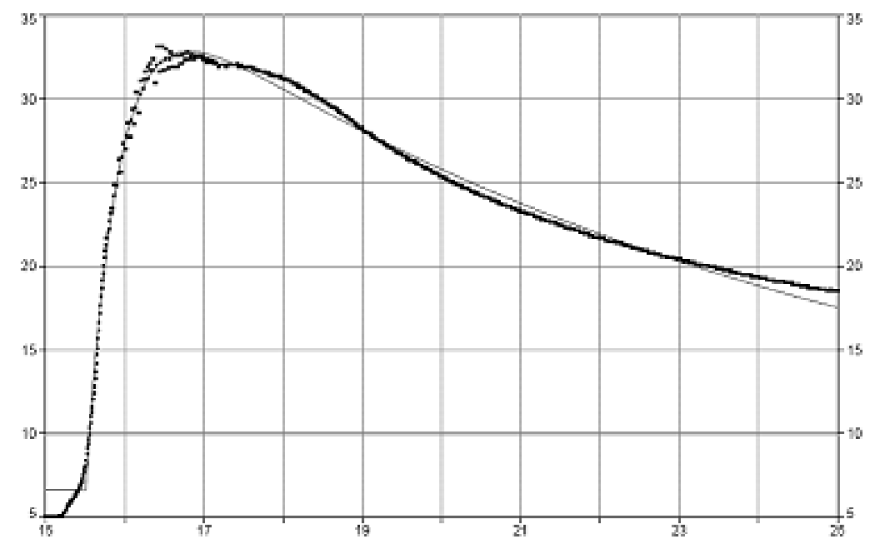

Figure 4b. A representative RCE and TableCurve fit by the difference between two exponentials.

From these fits, values for $\varphi$, voltage offset, $a$, and $b$ were obtained for our sample of 42 RCEs.

\section{Values and ratios.}

The voltage offset found from the model fits was highly correlated with the approximate estimate found by eye.

Values of the parameter "a" from our fits ranged from 0.43 to $5.5 \mathrm{~s}^{-1}$, (for $1 / \mathrm{e}$ times of 0.18 to 2.3 seconds) with a mean of 1.61 and median of $1.24 \mathrm{~s}^{-1}$ (0.62 and 0.80 seconds, respectively). It is instructive to inquire as to the $\mathrm{N}_{e}$ and $T_{e}$ dependences of "a" from our fits, so as to shed light on the physical mechanism for this decay. For each RCE, the density and temperature were determined as the average of 5 FPMU measurements from just before eclipse exit. In Figure 5 below is the relationship of " $a$ " to $\mathrm{N}_{\mathrm{e}}$ for our sample. For a sample size of 40 , the 0.0005 confidence level is at $r=0.50\left(r^{2}=0.25\right)$, so for our sample of 42 we are at a confidence level ${ }^{41}$ of better than 0.0005 for "a" vs. $\mathrm{N}_{\mathrm{e}}$.

$\mathrm{a}\left(\mathrm{s}^{-1}\right) \mathrm{vs} \mathrm{Ne}$

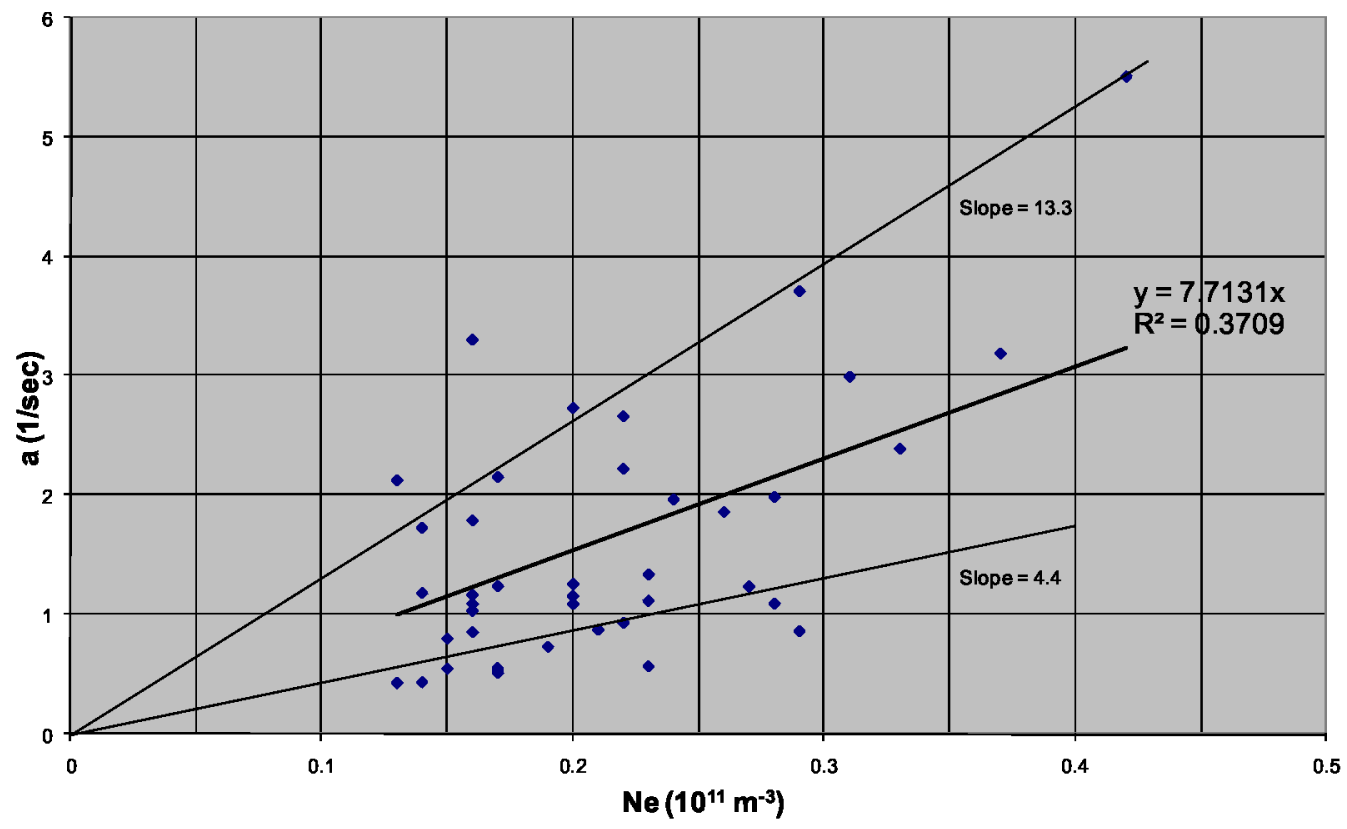

Figure 5. The value of " $a$ " versus electron density.

15

American Institute of Aeronautics and Astronautics 
The dependence of " $a$ " on $T_{e}$, on the other hand, is not statistically significant at even the .05 level. Since "a" is strongly correlated with $\mathrm{N}_{\mathrm{e}}$, "a" may be the decay time constant for ion collection, as we reasoned before.

Values of " $b$ " from our model fits ranged from 0.056 to $0.60 \mathrm{~s}^{-1}$ (for 1/e times of 1.7 to 18 seconds), with a mean of 0.21 and median of $0.18 \mathrm{~s}^{-1}$ (4.8 and 5.6 seconds, respectively). "b" shows significant correlations with both $\mathrm{N}_{\mathrm{e}}$ and $\mathrm{T}_{e}$, and for simple combinations of $\mathrm{N}_{e}$ and $\mathrm{T}_{e}$, the best correlation found was an exponential of " $b$ " with $\left(\mathrm{N}_{\mathrm{e}} \mathrm{T}_{\mathrm{e}}\right)^{1 / 2}$. See Fig. 6.

\section{b (s-1) vs $\sqrt{ }(\mathrm{Ne} * \mathrm{Te})$}

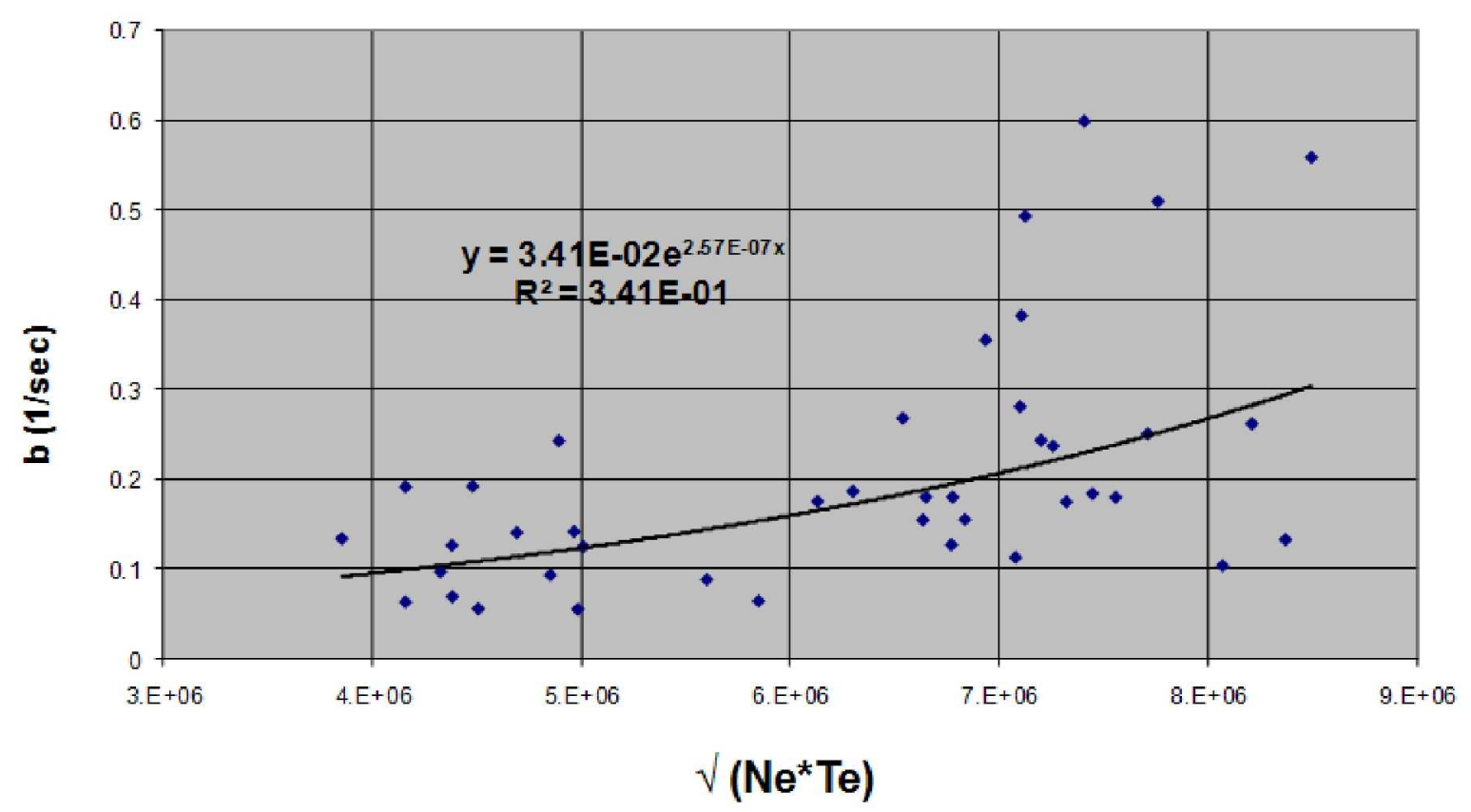

Figure 6. The value of $b$ versus $\sqrt{ }(\mathbf{N e T e})$.

Since electron collection is associated with $\left(\mathrm{N}_{\mathrm{e}} \mathrm{T}_{\mathrm{e}}\right)^{1 / 2}$, "b" may thus be the time constant for decay of electron collection, as we had also reasoned before.

Values of the ratio of $\mathrm{a} / \mathrm{b}$ ranged from 2.40 to 52.7 , with a mean of 10.6 and median of 6.3 .

We will call the value of $\varphi$ obtained from the TableCurve fit to each RCE " $\varphi_{\text {fit" }}$ ". $\varphi_{\text {fit }}$ ranged from 7.35 to 91.9 volts, with a mean of 28.7 and median of 23.2.

\section{Density and temperature dependences}

The amplitude $\varphi_{\text {fit }}$ from the TableCurve fits is related to $\left(\mathrm{N}_{\mathrm{e}} / \mathrm{T}_{\mathrm{e}}\right)^{1 / 2}$ as shown in Figure 7. 


\section{$\varphi$ vs $\sqrt{ }(\mathrm{Ne} / \mathrm{Te})$}

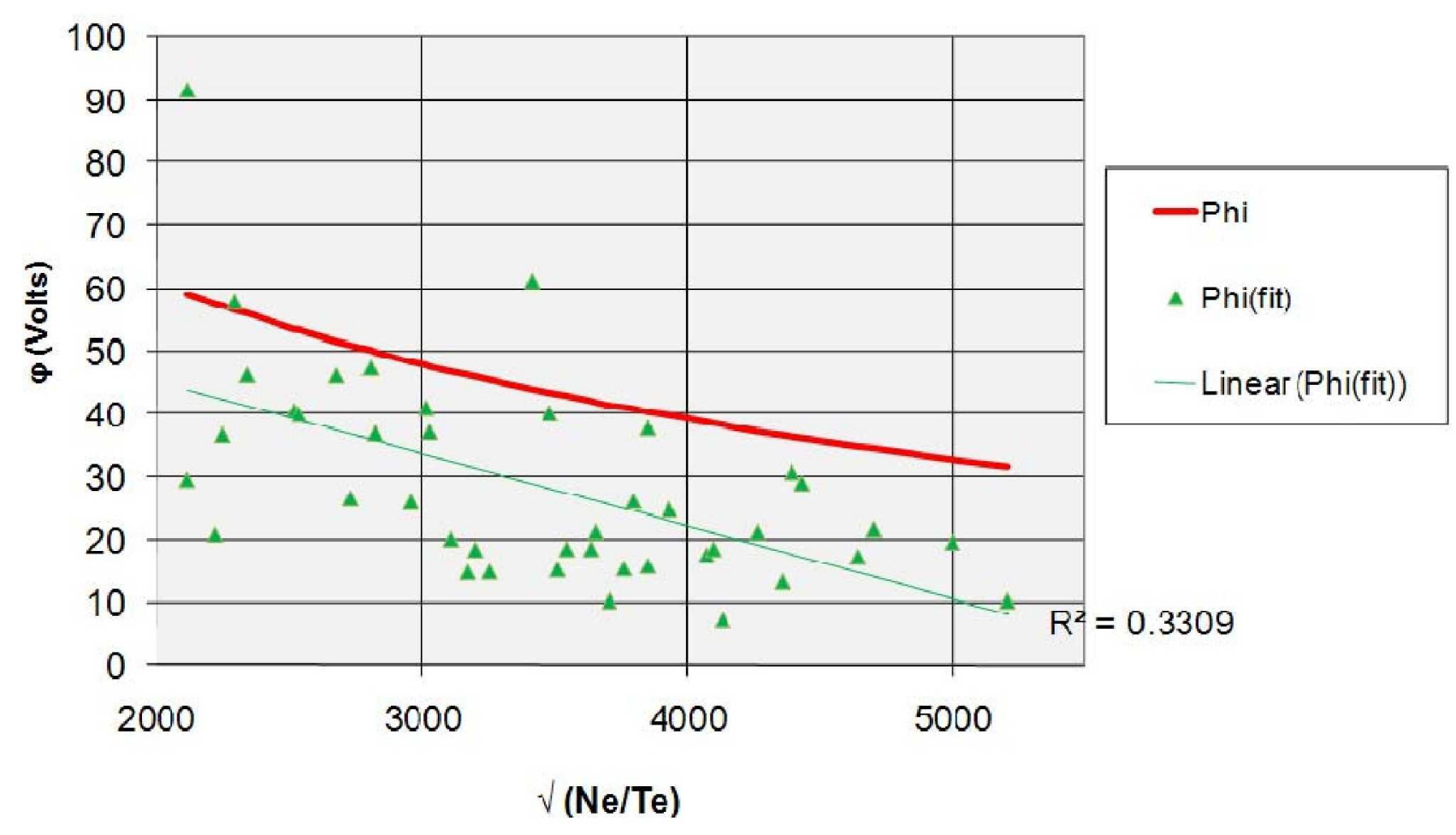

Figure 7. Amplitude versus $\sqrt{ }(\mathrm{Ne} / \mathrm{Te})$

In this figure Phi is the value of amplitude $\varphi$ predicted by Eqn. (31) which closely approximates the charging condition given by Eqn. (29). Here it can be seen that the theory predicts the peak value of the amplitude versus $\left(\mathrm{N}_{\mathrm{e}} / \mathrm{T}_{\mathrm{e}}\right)^{1 / 2}$ very well (except for two discrepant points), and also that the amplitude of the RCEs is linearly correlated with $\left(\mathrm{N}_{\mathrm{e}} / \mathrm{T}_{\mathrm{e}}\right)^{1 / 2}$ with a highly significant correlation coefficient of $\mathrm{r}^{2}=0.3309$.

We will discuss below why not all amplitudes of the RCEs lie along the predicted line.

\section{Dependence on ram angle of arrays}

Because the solar arrays are the sole electron collectors, and they are not oriented directly into the ram direction, their efficiency in producing charging should depend on the ram angle of the solar array at eclipse exit. In Figure 9, we see the ram angle dependence of the amplitude. Here, we have normalized the observed amplitude by dividing by $\varphi$ from equation (31) above, so as to take out all other dependences. 


\section{$\varphi_{\text {fit }} / \varphi$ vs Solar Array Ram Angle}

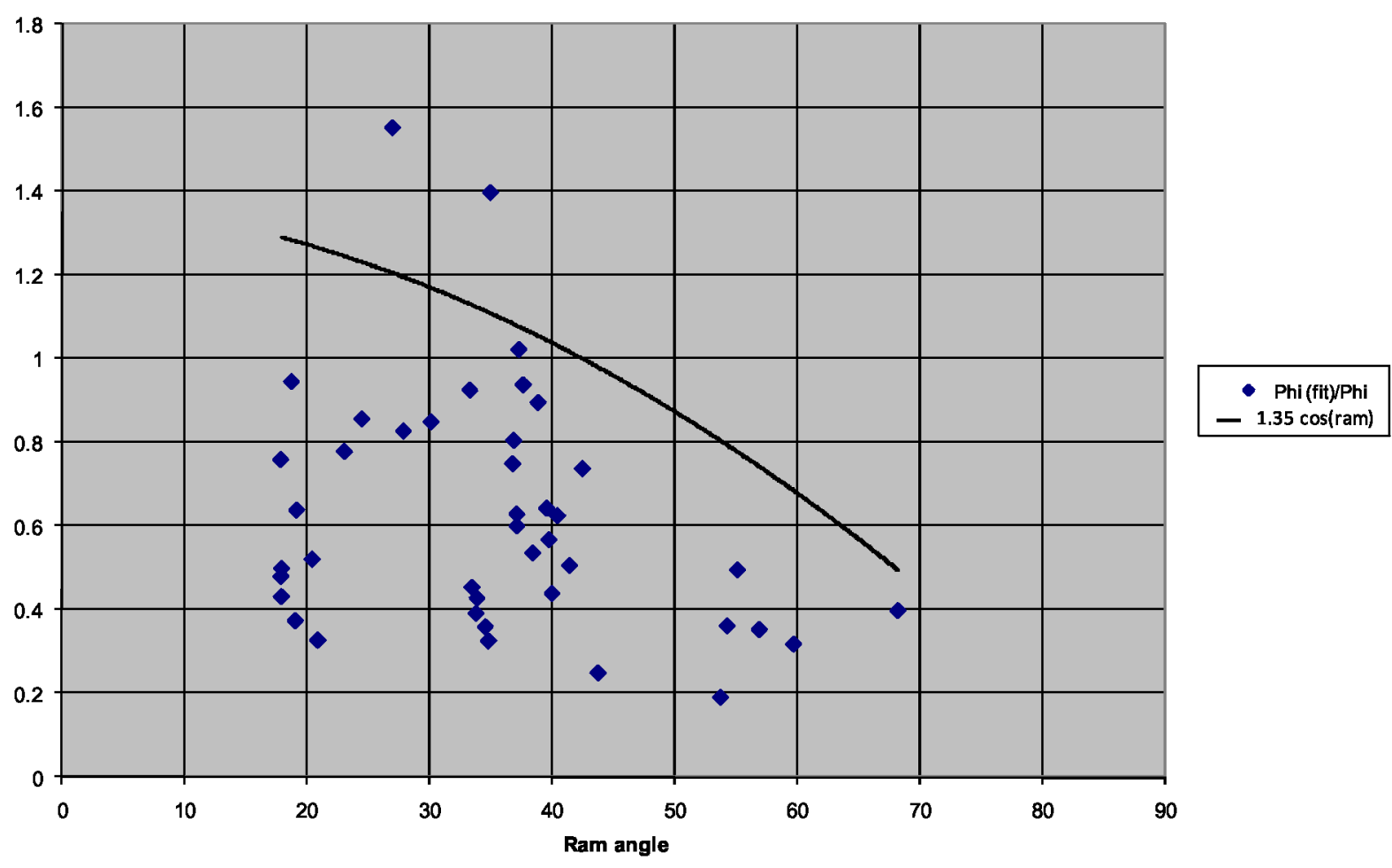

Figure 8. Normalized amplitude $\varphi$ from fits versus Solar Array Ram Angle.

Also plotted here is a cosine function, normalized to fit the maximum values of amplitude. It can be seen that the value of the peak amplitudes does indeed fall off as the cosine of the ram angle, as one would predict from the geometry. As in figure 7, the same two discrepant points spoil the excellent correlation.

\section{Other factors - ISS orientation, etc.}

There are many possible reasons why not all of the RCEs take on the amplitude calculated from the theory. First of all, the eclipse exit for a given RCE may have been under cloudy conditions, where the onset of voltage was coincident with the onset of ultraviolet photoemission. In this case, as we have noted before, the absolute amount of charging would be lowered by the negative charge loss due to photoemission.

Secondly, there may have been changes of $T_{e}$ and $N_{e}$ during the RCE duration. As ISS comes into daylight, one naturally expects $\mathrm{N}_{e}$ and $\mathrm{T}_{\mathrm{e}}$ both to increase. Since ISS moves about 1 orbital degree in 15 seconds, in order for the change to be important during the 20 seconds or so of the RCE, it would have to happen during about the first one or two degrees after eclipse exit. This is possible, if the gradient of $\mathrm{T}_{e}$ and/or $\mathrm{N}_{e}$ are steep enough at the terminator. We may be seeing the effects of high gradients in $\mathrm{N}_{e}$ and $\mathrm{T}_{\mathrm{e}}$ in the RCEs with complex structure. Also, so-called "density dropouts" have been observed in the ionosphere, where the density decreases and the temperature increases (so as to equalize the pressure) on very short distance scales. Examination of the time history of $T_{e}$ and $N_{e}$ during some of our observed RCEs shows that this effect may make for an occasional discrepant point.

Thirdly, during the time interval over which the data for the model fits was obtained, there were really three functioning arrays on ISS, but the third array was not tracking (and, in fact one half was pointing in a different direction than the other). Thus, depending on beta angle, it could supply more or less electron collection from the illuminated half or ion collection area from the unilluminated half. Also, drag reduction modes of flying ISS, including the so-called night-glider mode, with the solar array wings partially or fully feathered to the velocity vector, can cause large variations in the electron collection at eclipse exit. 
Fourth, power management may have taken place during the RCE. Usually, at eclipse exit, all strings on the active arrays are unshunted (active). However, shortly after the arrays start producing power, power management algorithms start turning off strings to maintain the only the current needed to keep the batteries fully charged. Depending on the state of battery charge, this may occur sooner or later in the orbit. Shunted strings are disconnected from system ground, and will not contribute to ISS current balance.

Fifth, small changes in ISS orientation at eclipse exit (there is a deadband in angle around the nominal orientation, with corrections at the ends of the deadband) may make a big difference in ion collection. Turning the ion collection areas of the Russian segments even a little bit into or out of the ram can be important. Also, during reboost and at other times, the ISS orientation can vary from the normal $+\mathrm{XVV}$ attitude.

Sixth, in our simple-minded derivation of the ion and electron collection, we have ignored all magnetic field effects, including $\mathrm{vxB} \cdot 1$ effects. Depending on the magnetic latitude and longitude of eclipse exit, this may change the relative proportions of array electron and ion collection.

Some of these effects may be estimated from detailed examination of the ODRC data, but that must remain for forward work. Suffice it to say that the simple theory presented here works well for the RCEs of simple shape, and there is enough flexibility in orbital conditions at eclipse exit to make it plausible for all of the RCEs.

\section{Predictions for ISS Final Assembly and Peak Solar Activity}

As the number of active and tracking electron-collecting arrays on ISS increases, without a concomitant increase in the structure ion collecting area, we may expect the RCEs to be of higher amplitude. Putting in values for the increased electron collection and ion collection area $\left(A_{S A}=12.6 \mathrm{~m}^{2}, A_{\text {mast }}=10 \mathrm{~m}^{2}\right)$ into the calculation of $\varphi$ above, and using a numerical approximation, we have the equation below and Figure 9 showing predictions for RCE amplitude versus $\left(\mathrm{N}_{\mathrm{e}} / \mathrm{T}_{\mathrm{e}}\right)^{1 / 2}$ for the 4 array case:

$$
\ln \varphi^{\prime}=5.2147-0.01741 \sqrt{ }\left[\left(\mathrm{N}_{\mathrm{e}} / \mathrm{T}_{\mathrm{e}}\right)^{1 / 2}\right]
$$

\section{$\varphi$ vs $\sqrt{ }(\mathrm{Ne} / \mathrm{Te})$}

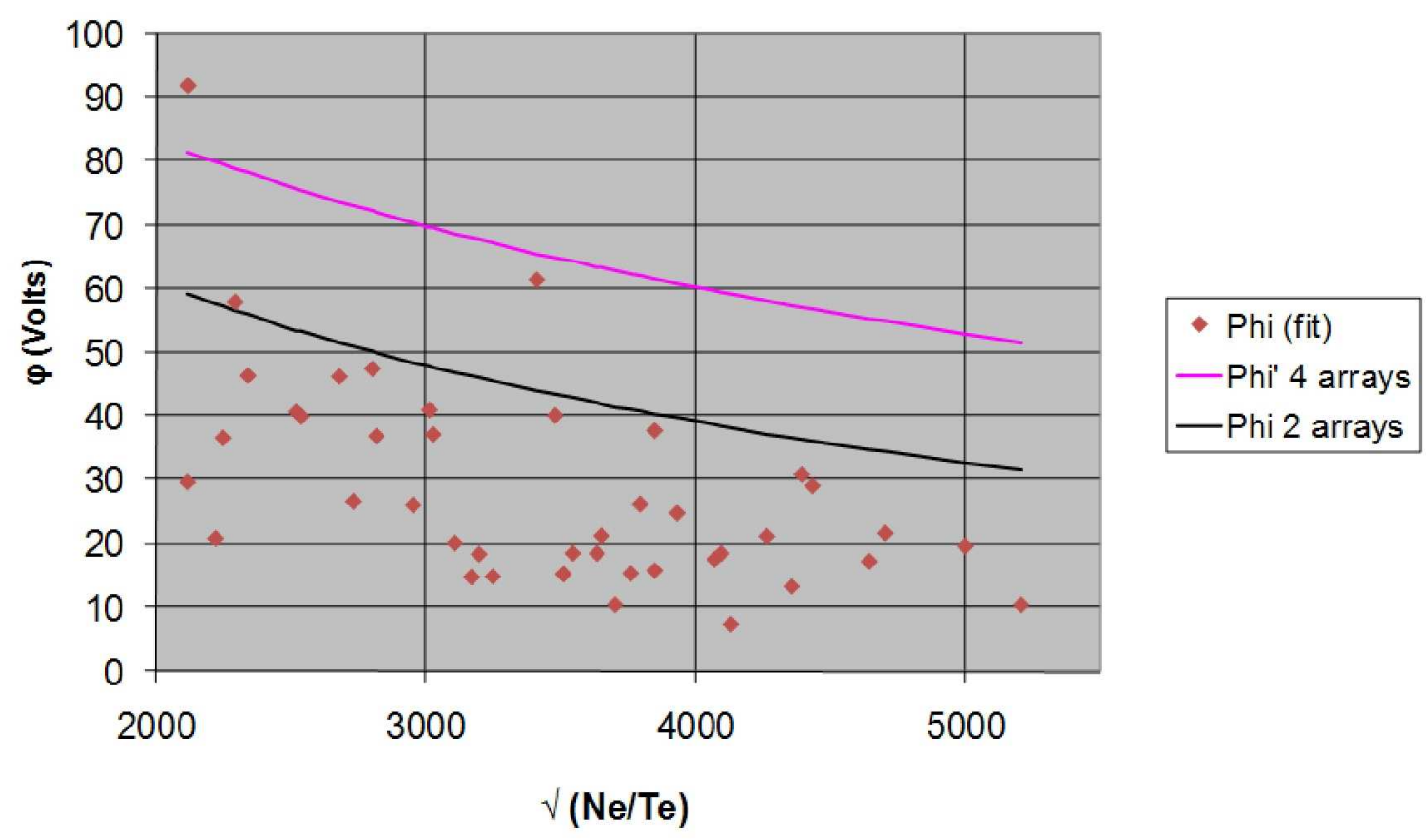

Figure 9. Peak amplitude predictions for 4 active arrays. 
Figure 9 shows that for the full 4 arrays in operation, peak RCEs of amplitude at least 81 volts are predicted, with routine values in the $60-70$ volt range. Putting in average values of " $a$ " and " $b$ " into equation (4), and calculating a peak voltage at that time, these amplitudes predict that the peak voltages are likely to be in the 45-55 volt range. Note also that for 4 solar arrays active, eqn. (30) shows that RCEs extend to higher values of $\left(\mathrm{N}_{\mathrm{e}} / \mathrm{T}_{\mathrm{e}}\right)$ than for 2 arrays, so we may expect that in 4 solar array operational conditions, there will be a higher percentage of eclipse exits with some degree of rapid charging. And, from Figure 8, we might expect that for a maximum ram condition the peaks will be about a factor of 1.3 times as great as from $\varphi$ alone, and this makes for a maximum peak amplitude of about 105 volts, with peak voltages in the 75 volt range.

These predictions are based on low solar activity, when it can be expected that $\left(\mathrm{N}_{\mathrm{e}} / \mathrm{T}_{\mathrm{e}}\right)$ is low when coming out of eclipse. At times of high solar activity $\left(\mathrm{N}_{\mathrm{e}} / \mathrm{T}_{\mathrm{e}}\right)$ will be higher, on the average, and it is less likely that severe RCEs will occur. However, as has already been pointed out ${ }^{21}$, during solar geomagnetic substorms (which occur preferentially during times of high solar activity), the variability in both $\mathrm{N}_{\mathrm{e}}$ and $\mathrm{T}_{\mathrm{e}}$ are greatly enhanced, and periods of low $\left(\mathrm{N}_{\mathrm{e}} / \mathrm{T}_{\mathrm{e}}\right)$ may still be expected.

\section{A. Probability of dielectric breakdown from RCEs}

Because RCEs represent events where the structure potential becomes highly negative before all dielectric surfaces are neutralized, we should not expect that the electric fields developed across dielectrics are as great (compared to the amplitude of structure charging) as they would be for normal charging. It is the potential difference between the underlying structure and the dielectric surface that produces the electric fields that are important in dielectric breakdown, after all. One may be justified in asking, then, what is the potential difference for dielectric materials during an RCE? In general, dielectric surfaces will be neutralized by ion collection, so one may compare the instantaneous structure potential with the surface potential on the dielectric, which is changing from $\varphi$ to near zero on the dielectric ram ion charging timescale for that particular dielectric. Looking at the time equation for charging, we can postulate that

$$
\mathrm{V}_{\mathrm{pk}}-\mathrm{V}_{\mathrm{di}}=\varphi\left[\mathrm{e}^{-\mathrm{at}}-\mathrm{e}^{-\mathrm{bt}}-\mathrm{e}^{-\mathrm{ct}}\right]
$$

where " $\mathrm{c}$ " is the charging timescale for the dielectric (di) in question, and $t$ is the time of the peak from equation (33),

$$
t_{p k}=(\ln a-\ln b) /(a-b)
$$

Identifying the timescale a as the ram ion charging timescale for at least one type of ISS structure dielectric, we find for that dielectric, $c=a$ and,

$$
\begin{gathered}
\left|\mathrm{V}_{\mathrm{pk}}-\mathrm{V}_{\mathrm{di}}\right|=\varphi\left[\mathrm{e}^{-\mathrm{bt}}\right] \text {, so that at } \mathrm{t}_{\mathrm{pk}} \text {, we have } \\
\left|\mathrm{V}_{\mathrm{pk}}-\mathrm{V}_{\mathrm{di}}\right|=\varphi\left[(\mathrm{b} / \mathrm{a})^{(\mathrm{b} / \mathrm{a}-\mathrm{b}])}\right] .
\end{gathered}
$$

Putting in values typical of $a$ and $b$ for RCEs (1.61 and 0.21 , respectively), we find

$$
\left|\mathrm{V}_{\mathrm{pk}}-\mathrm{V}_{\mathrm{di}}\right|=\varphi\left[(0.13)^{0.15}\right]=\varphi[0.74]
$$

Thus, we may expect this dielectric to have a peak potential difference across it of about 0.74 of the maximum peak amplitude $\varphi$. For a 105 volt amplitude, which may sometimes be the case for 4 solar arrays operational, this implies a dielectric potential difference of perhaps 78 volts. For ISS chromic acid anodized aluminum (our type 1) material, a dielectric breakdown strength of 66-82 $\mathrm{V}$ has been found ${ }^{22,23}$. Thus, it seems theoretically possible that ISS type 1 anodization may break down due to RCEs when there are 4 solar arrays active. However, Schneider et al. also used a 10 minute waiting time to detect arcs near the threshold, whereas our charging peaks are on the order of 4 seconds wide. If the arcing is purely stochastic, within a 4 second time period we might expect a probability of one in $\sim 150$ that any given RCE would produce an arc. If an arc does occur, however, it may be of high amplitude (perhaps 10 amps) and duration ( $5 \mathrm{~ms}$ or more) and may thus expend several Joules of energy ${ }^{23}$. Type 2 anodization, much thicker and more robust, should arc very seldom if at all. We predict, therefore, that after several hundred RCEs on 
an ISS with 4 active solar arrays, there may occur one or more arcs on ISS type 1 anodization. If the ISS program is concerned about the effects of individual dielectric breakdowns, a mitigation technique (either the use of PCUs or an alternative such as feathering the arrays ${ }^{24}$ ) can be adopted for the first few minutes of eclipse exit, to prevent possible arcing from large RCEs or normal charging with 4 active arrays. If arcs do occur, they will be easily seen in the floating potentials of a continuously operating high time resolution instrument such as the FPMU.

\section{EWB Model}

An EWB model was produced of ISS at Assembly Complete for eclipse exit with the following parameters: $\mathrm{N}_{\mathrm{e}}=$ $5.1 \times 10^{10} \mathrm{~m}^{-3}, \mathrm{~T}_{\mathrm{e}}=0.167 \mathrm{eV}$, ram angle at eclipse exit $=26.3^{\circ}$, latitude of eclipse exit $=-48.5^{\circ}$, altitude $=341 \mathrm{~km}$, and $\mathrm{v}=7.7 \mathrm{~km} / \mathrm{s}$. The solar array electron and ion current collection curve in EWB was adjusted so that it matched that expected from the RCE Theory at the plasma densities and temperatures given. Ram ion current collection areas were also adjusted to give the correct ratio of ion collection currents to array electron collection currents. The EWB model found extrema in the ISS potentials of -11 and -52 volts, with the average structure potential of $-31 \mathrm{~V}$, approximately the value predicted from the RCE Theory. A plot of the potentials is shown in Figure 10. The major differences in potential across the ISS structure are due to vxB 1 .

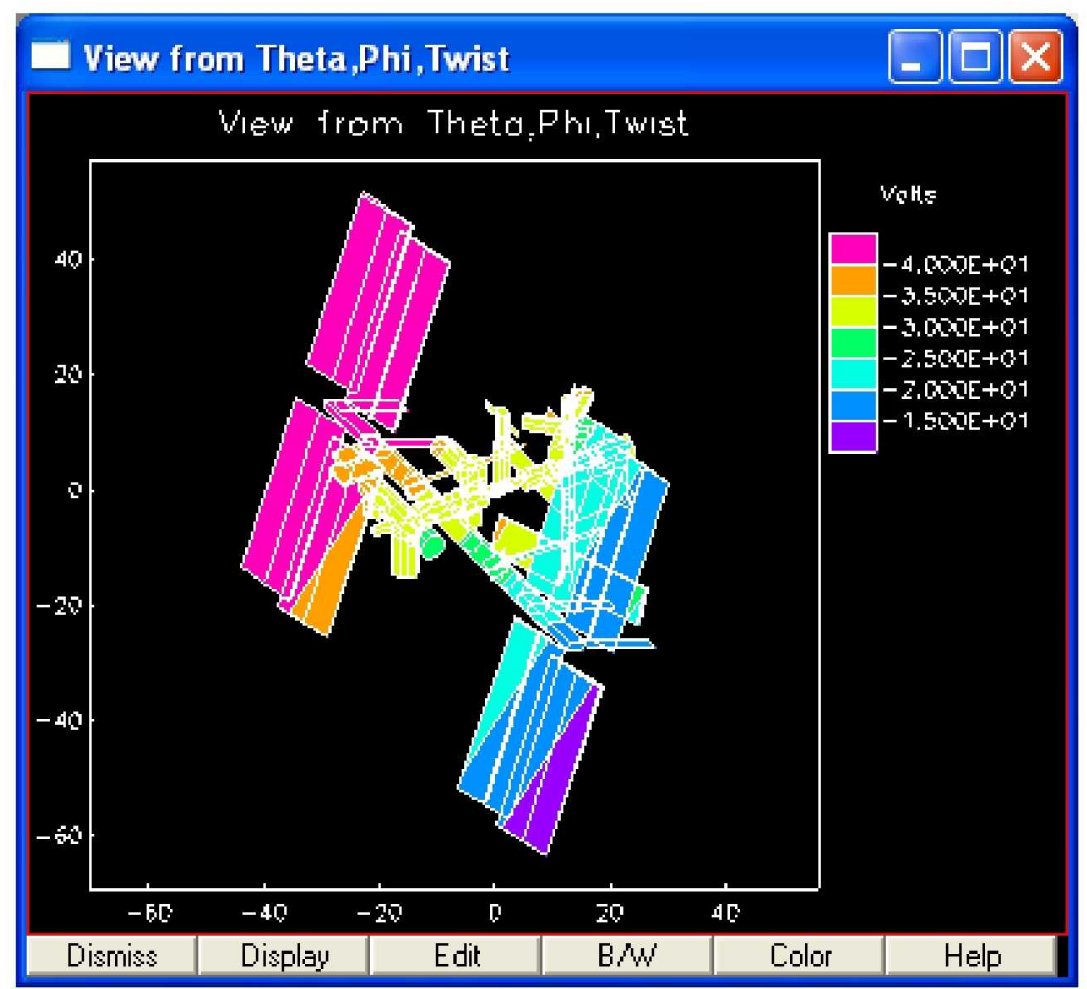

Figure 10. Structure potentials on ISS at Assembly Complete configuration for representative plasma conditions at eclipse exit, showing vxB·l effects. 


\section{Conclusions and Predictions}

\section{A. No Ad-hoc Physics}

We have shown that it is possible to model the RCEs with a simple physical model assuming the initial condition of uncharged coverglasses, focused ram ion collection and array electron collection through a sheath.

\section{B. Model Agreement with FPMU Observations}

Our model agrees with the observed maximum amplitude and time behavior of RCEs, as well as their dependences on electron density $\mathrm{N}_{\mathrm{e}}$ and temperature $\mathrm{T}_{\mathrm{e}}$. The model also predicts that RCEs will decay into normal charging, which is also in agreement with observations. Finally, the model shows that RCEs of large amplitude will not occur for large values of $\left(\mathrm{N}_{e} / \mathrm{T}_{\mathrm{e}}\right)$, also in accord with observations.

\section{Predictions for Dielectric Breakdown at Assembly Complete}

We have calculated whether dielectric breakdown can occur on ISS anodized aluminum surfaces, and have found that with 4 active arrays, dielectric breakdown is likely to occur after several hundred RCEs have happened. In addition, we find that the probability of RCE occurrence is enhanced by having 4 solar arrays active.

\section{Predictions for Solar Max}

Because $\left(\mathrm{N}_{\mathrm{e}} / \mathrm{T}_{\mathrm{e}}\right)$ is, on average, higher at eclipse exit near the maximum of the solar activity cycle, this should make the RCEs rarer than at the present time. However, during solar geomagnetic substorms, the likelihood of RCEs increases, due to the wider than normal deviations from average $\left(\mathrm{N}_{\mathrm{e}} / \mathrm{T}_{\mathrm{e}}\right)$ conditions at those times ${ }^{21}$.

\section{E. Future Use of Plasma Experiments on ISS}

ISS has shown that it is a wonderful platform for plasma experiments in LEO. Even with instruments that worked for only a short time (FPP), or for limited time periods (FPMU), and with a smaller number of active arrays, the knowledge that has been gained about LEO spacecraft charging has been dramatic. With the coming of plasma instruments on the Japanese Experiment Module and the increased power requirements on the solar arrays, which will prevent their shunting after the first few seconds of power generation, the opportunities for investigating ISS charging will greatly increase. In order to fully understand the RCEs, the following data and experiments would be desirable: infrared and ultraviolet fluxes to help determine the instants when solar array voltages are turned-on and photoemission starts, occasional periodic on/off PCU cycles just after eclipse exit to determine the RCE and normal charging baselines, continuous plasma parameter and floating potential determination so we won't miss any RCEs or discharges due to RCEs, and floating potential determinations during docking and periods when Shuttle or $\mathrm{CEV}$ are docked to see how the presence of the current collection of these bodies changes ISS charging. Because of its size, high voltage arrays, and interesting structure-conductor and solar cell geometries, the ISS and its plasma interactions will undoubtedly continue to surprise and enlighten us.

\section{Acknowledgments}

The authors would like to thank Chuck Swenson for discussions about the time constants and time resolution of the FPMU instruments. Also, discussions with Todd Schneider about the nature of the exposed conductors on the Russian thermal blankets are gratefully acknowledged. Thanks also to Nick Riedel for drawing Figure 2.

BKapton is a registered trademark of Dupont de Nemours, Co. 


\section{References}

${ }^{1}$ Ferguson, D.C., Snyder, D.B., and R. Carruth, Report of the Joint Workshop of the Space Station Freedom Plasma Interactions and Effects Working Group, the Space Station Freedom Plasma Working Group, and the Space Station Freedom EMI/EMC and Electromagnetic Effects Working Group on Evaluation of Impacts of Space Station Freedom Grounding Configurations, May 22-24, 1990. Final Report, Aug. 21, 1990. Available through NASA Glenn Research Center.

${ }^{2}$ Carruth, M.R., Jr., Schneider, T., McCollum, M., Finckenor, M., Suggs, R., Ferguson, D., Katz, I., Mikatarian, R., Alred, J., and Pankop, C., "ISS and Space Environment Interactions Without Operating Plasma Contactor," 39th Aerospace Sciences Meeting and Exhibit, Reno, Nevada, Jan. 8-11, 2001, AIAA-2001-0401.

${ }^{3}$ Chock, R.C. "NASCAP/LEO Simulations, SSF Solar Cell Geometries," Minutes of the Electrical Grounding Tiger Team Meeting, Boeing Trade Zone, Huntsville, Alabama, May 14-17, 1991.

${ }^{4}$ Katz, I., Davis, V.A., Kuharski, R., Jongeward, G., and Mandell, M., "Environment WorkBench Calculations of Space Station Floating Potentials," Minutes of the Electrical Grounding Tiger Team Meeting, Boeing Trade Zone, Huntsville, Alabama, May 14-17, 1991.

${ }^{5}$ Felder M.C., et al., "Results of Tests Conducted in Tank 5 for Interactions Between Space Station Freedom and Plasma," PIR\#268, NASA LeRC (now GRC), January 22, 1993.

${ }^{6}$ Ferguson, D.C. and Hillard, G.B., "In-Space Measurement of Electron Current Collection by Space Station Solar Arrays," AIAA Paper \#95-0486, 1995.

${ }^{7}$ Davis, V.A., Gardner, B.M., and Guidice, D.A., "PASP Plus solar array parasitic current collection flight results,"

IEEE Transactions on Plasma Science, Volume 26, Issue 1, Feb 1998 Page(s):46 - 58.

${ }^{8}$ Ferguson, D.C., "Comparison of Electron Current Collection by Space Station Solar Arrays as Measured by SAMPIE and PASP Plus," in the Photovoltaic Array Space Power Plus Diagnostics (PASP Plus) Experiment Final Report, D.A. Guidice, V.A. Davis, H.B. Curtis, D.E. Hastings, F.L.Knight, D.C. Marvin, K.P. Ray, P.S. Severance, J.D. Soldi, M. Van Riet, co-authors, PLTR-97-1013, March, 1997.

${ }^{9}$ Schneider, T.A., Vaughn, J.A., Minow, J.I., Hwang, K-S, Wright, K.H., Reddell, B., Alred, J., Mikatarian, R., Leung, P. and Koontz, S., "Current Collection Characteristics of International Space Station Russian Thermal Blanket Material," AIAA-2006$867,2006$.

${ }^{10}$ Chock, R. and Ferguson, D.C., "Environments Workbench - An Official NASA Space Environments Tool," Proceedings of the 32nd Intersociety Energy Conversion Engineering Conference, Wash. DC, Paper IECEC-97452, 1997.

${ }^{11}$ Ferguson, D.C., "FPP Results_Final Report," IEEE Transactions on Plasma Science, Volume: 37, Issue: 2, Feb. 2009, page(s): 369-374.

${ }^{12}$ Ferguson, D. C. and Morton, T. L., 'An empirical model of ISS charging, based on FPP and ODRC data of 04/11/01 Thru 04/13/01. Is Shunting One Array at Dawn Always a Good EVA Hazard Control?," Aug. 2, 2001. Presentation to the ISS PCU Tiger Team.

${ }^{13}$ Ferguson, D.C., "Charging Of The International Space Station Due To Its High Voltage Solar Arrays," 2001, Proceedings of the XVIIth Space Photovoltaic Research and Technology Conference.

${ }^{14}$ Ferguson, D.C. and Gardner, B.M., "Modeling International Space Station (ISS) Floating Potentials," 40th AIAA Aerospace Sciences Meeting \& Exhibit, Reno, NV, Jan. 14-17, 2002.

${ }^{15}$ Ferguson, D.C., "V X B Effects on Space Station," 2nd International Energy Conversion Engineering Conference, Providence, Rhode Island, Aug. 16-19, 2004, AIAA-2004-5669.

${ }^{16}$ Mandell, M.J., Davis, V.A., Gardner, B., and Jongeward, G., "Electron Collection by International Space Station Solar Arrays," $8^{\text {th }}$ Spacecraft Charging Technology Conference, Huntsville, AL, October, 2003.

${ }^{17}$ Chen, Francis F., 2008, "Use of Langmuir Probes in RF Plasmas," Institute of Nuclear Energy Research, Taiwan, March 2008.

${ }^{18}$ Kerslake, T.W. and Scheimann, D.A. (NASA TM-2005-213988), Off-Nominal Performance of the International Space Station Solar Array Wings Under Orbital Eclipse Lighting Scenarios, AIAA-2005-5671.

${ }^{19}$ Craven, P.D., Wright, K.H., Jr., Minow, J.I., Coffey, V.N., Schneider, T.A., Vaughn, J.A., Ferguson, D.C., and Parker, L.N., "Survey of International Space Station Charging Events," 47th AIAA Aerospace Sciences Meeting Including The New Horizons Forum and Aerospace Exposition, 5 - 8 January 2009, Orlando, Florida, AIAA 2009-119.

${ }^{20}$ TableCurve 2D v 4.07. SPSS Inc., 444 N. Michigan Avenue, Chicago, IL 60611.

${ }^{21}$ Ferguson, D.C., Hillard, G.B., Morton, T.L., and Personen, R. "ISS FPP Ionospheric Electron Density and Temperature Measurements - Results, Comparison with the IRI-90 model, and Implications for ISS Charging," 41st AIAA Aerospace Sciences Meeting \& Exhibit, Reno, NV, Jan. 6-9, 2003.

${ }^{22}$ Schneider, T.A., Carruth, M.R., Jr., and Hansen, H.J., "Minimum Arc Threshold Voltage Experiments on Extravehicular Mobility Unit Samples," AIAA-2002-1040, 2002.

${ }^{23}$ Black, T.P., Schneider, T.A., Tiepel, B.R., Kramer, L., and Leung, P., "Plasma-Induced Dielectric Breakdown of Anodized Aluminum Surfaces," 44th AIAA Aerospace Sciences Meeting and Exhibit, 9 - 12 January 2006, Reno, Nevada, AIAA 2006871.

${ }^{24}$ Ferguson, D.C., "Alternatives to the ISS Plasma Contacting Units," AIAA-2002-934, AIAA Aerospace Sciences Meeting and Exhibit, 40th, Reno, NV, Jan. 14-17, 2002. 
${ }^{25}$ Wright, Jr., K. H., Swenson, C.M., Thompson, D.C., Barjatya, A., Koontz, S.L., Schneider, T.A., Vaughn, J.A., Minow, J.I., Craven, P.D., Coffey, V.N., Parker, L.N., and Bui, T., "Charging of the International Space Station as Observed by the Floating Potential Measurement Unit: Initial Results," IEEE Trans. Plasma Science, Vol. 36, Issue 5, Part 2, pp. 2280 - 2293, 2008.

${ }^{26}$ Coffey, V.N., Wright, Jr., K.H., Minow, J.I., Schneider, T.A., Vaughn, J.A., Craven, P.D., Chandler, M.O., Koontz, S.L., Parker, L.N. and Bui, T.H., "Validation of the Plasma Densities and Temperatures From the ISS Floating Potential Measurement Unit," IEEE Trans. Plasma Science, Vol. 36, Issue 5, Part 2, pp. 2301- 2308, 2008.

${ }^{27}$ Swenson, C.M., Thompson, D., and Fish, C., "The Floating Potential Measurement Unit," 41st AIAA Aerospace Sciences Meeting and Exhibit, Reno, NV, Jan. 6-9, 2003, AIAA paper \# 2003-1081.

${ }^{28}$ Swenson, C.M., Fish, C., and Thompson, D., "Calibrating the Floating Potential Measurement Unit," 8th Spacecraft Charging Technology Conference, Oct. 20-24, 2003, Huntsville, AL, NASA/CP-2004-213091.

${ }^{29}$ Swenson, C.M., Thompson, D., and Fish, C., "The ISS Floating Potential Measurement Unit," 9th Spacecraft Charging Technology Conference, April 4-8, 2005, Tsukuba, Japan.

${ }^{30}$ Rodgers, D., "Spacecraft Plasma Interaction Guidelines and Handbook, version 0.3," European Space Agency, QinetiQ/KI/SPACE/HB042617, 30 September 2004, pp. 19-20.

${ }^{31}$ Huba, J.D., NRL PLASMA FORMULARY, 2004 Revised, p. 29.

${ }^{32}$ Ferguson, D.C., Vayner, B.V., Galofaro, J.T., Hillard, G.B., Vaughn, J., and Schneider, T., "NASA GRC and MSFC Space Plasma Arc Testing Procedures," IEEE Trans. Plasma Science, Vol. 34, Issue 5, p. 1950, 2006.

${ }^{33}$ Barjatya, A., Swenson, C.M., Thompson, D.C., and Wright, Jr., K.H., "Invited Article: Data analysis of the Floating

Potential Measurement Unit aboard the International Space Station," Review of Scientific Instruments 80, 041301, 2009.

${ }^{34}$ Barsamian, H., Mikatarian, R., Alred, J., Minow, J., and Koontz, S., "ISS Plasma Interaction: Measurements and Modeling," presented at the 8th Spacecraft Charging Technology Conference, Huntsville, AL, 20-24 October 2003.

${ }^{35}$ Mikatarian, R., Barsamian, H., Alred, J., Kern, J., Minow, J., and Koontz, S., "Electrical Charging of the International Space Station," AIAA-2003-1079, presented at the AIAA ACM, Reno, NV, January, 2003.

${ }^{36}$ Reddell, B., Alred, J., Mikatarian, R., Minow, J., Koontz, S. and Kramer, L., "Analysis of ISS Plasma Interaction," AIAA2006-0865, 44th AIAA Aerospace Sciences Meeting, Reno, NV, January 2006.

${ }^{37}$ EWB 5.0 User's Reference Manual, NASA/Glenn Contract NAS\#-25347, July 31, 1997.

${ }^{38}$ Mikatarian, R.R., Barsamian, H.R., Kern, J.W., Koontz, S.L., Roussel, J-F., "Plasma Charging of the International Space Station," 53rd International Astronautical Congress, The World Space Congress - 2002, 10-19 Oct 2002, Houston Texas.

${ }^{39}$ Grard, R.J.L., Knott, K., and Pederson, A., "The influence of photoelectron and secondary electron emission on electric field measurements in the magnetosphere and solar wind," in Photon and Particle Interactions with Surfaces in Space, R.J.L. Grard (ed.), pp. 163 - 189, D. Reidel Publishing Company, Dordrecht-Holland, 1973.

${ }^{40}$ Hastings, D., and Garrett, H., Spacecraft Environment Interactions, Cambridge University Press, 1996.

${ }^{41}$ Rummel, R.J., Understanding Correlation, Honolulu: Department of Political Science, University of Hawaii, 1976.

${ }^{42}$ Ferry, M., author's visit with Lockheed Martin Space Systems Company, June 11, 2001, private communication. 


\section{A Theory for Rapid Charging Events on the International Space Station}

Dale C. Ferguson, Paul D. Craven, and Joseph I. Minow NASA Marshall Space Flight Center, Huntsville, Alabama, 35812 and

Kenneth H. Wright, Jr. University of Alabama-Huntsville, Huntsville, Alabama, 35899 


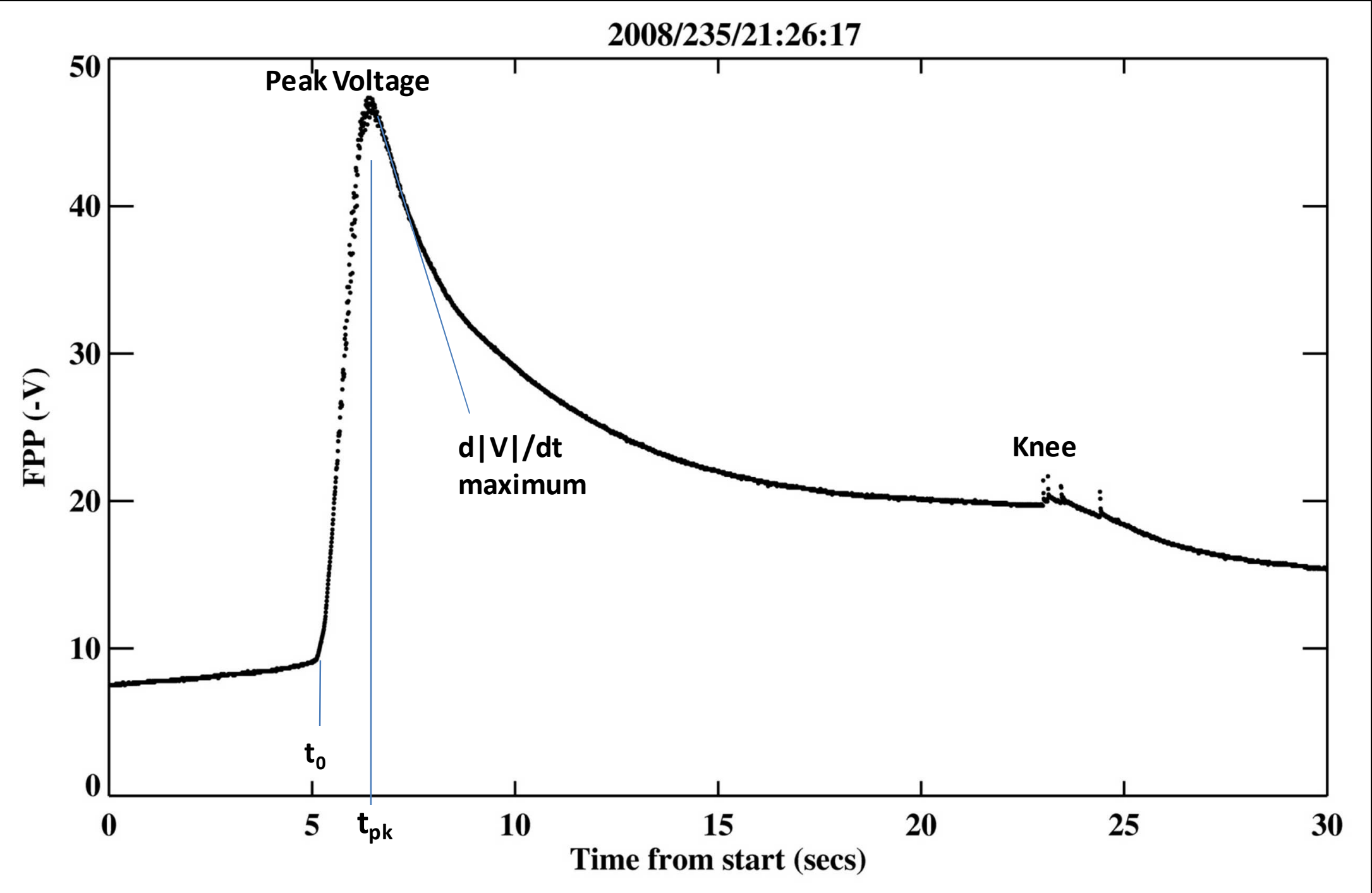




\section{Rapid Charging Event (RCE) Scenario}

When ISS comes out of eclipse, voltage turns on rapidly

Solar cell coverglasses are initially at potential of underlying cell because of capacitive coupling

Electron current choking on solar arrays is not in effect, since the coverglasses and gap kapton are not near plasma potential

Until coverglasses can charge, high values of current collection allow ISS to charge rapidly to high negative voltages

Potential will decay as electrons and ions can charge surfaces to near plasma potential 


\section{Timescales for ISS charging in a plasma of $\mathrm{Ne}=2 \times 10^{10} \mathrm{~m}^{-3}$ and $\mathrm{Te}=2000 \mathrm{~K}$}

Dielectric

thickness,

Type of Surface

ISS Structure type 1

ISS Structure type 2

ISS Solar Array

ISS Structure type 1

ISS Structure type 2

ISS beta cloth

ISS CIC (cell gap)

ISS Solar Array

m)

1.30E-06

$1.30 \mathrm{E}-05$

1.50E-04

1.30E-06

1.30E-05

7.60E-04

7.60E-05

$1.50 \mathrm{E}-04$
$\mathrm{C} / \mathrm{A}\left(\mathbf{F} / \mathbf{m}^{2}\right)$

Type of charging

$1 / \mathrm{t}(1 / \mathrm{s})$

t (sec)

3.40E-05 Ram Ion

3.29E-02 3.04E+01

3.40E-06 Ram Ion

3.29E-01

3.04E+00

2.95E-07 Ram Ion

$3.80 \mathrm{E}+00$

2.63E-01

3.40E-05 Focused Ram Ion

2.30E-01

$4.34 \mathrm{E}+00$

3.40E-06 Focused Ram Ion

2.30E+00

4.34E-01

5.82E-08 Ram Ion

$1.92 \mathrm{E}+01$

5.20E-02

5.82E-07 Thermal Electron

$4.32 \mathrm{E}+00$

2.31E-01

2.95E-07 Thermal Electron

$8.53 E+00 \quad 1.17 E-01$ 


\section{Geometry of the ISS solar array Wing Assembly}

Factory Verification - Wing Assembly (Typical Circuit) 400 Series Connected So ar Cells

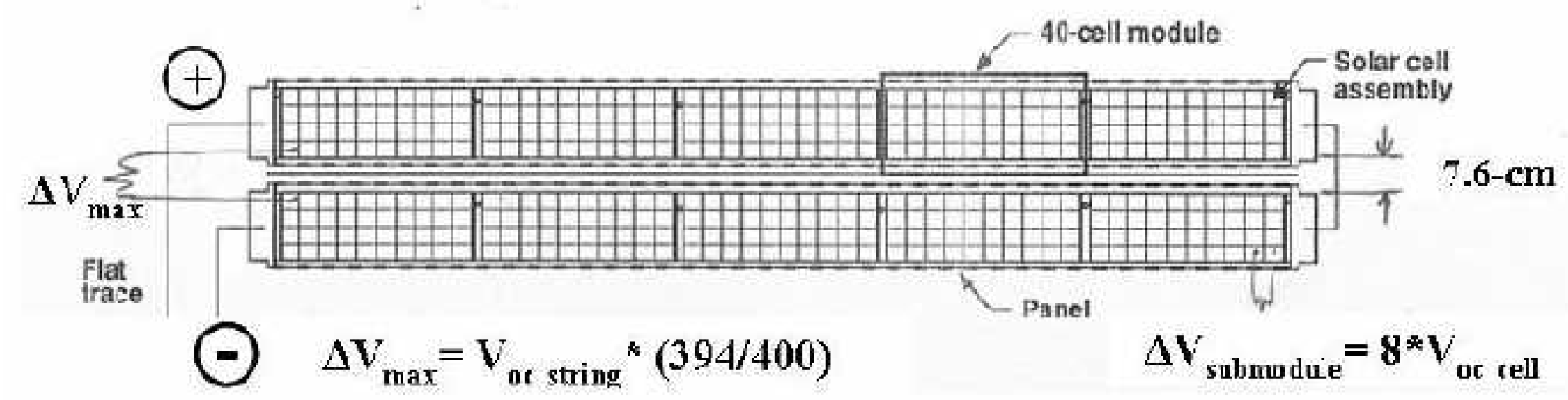




\section{Current Balance Theory - $\phi=$ Amplitude}

\section{(no coverglass charging)}

$$
\begin{aligned}
& \varphi / 160=\left[1-\left(\mathrm{J}_{\mathrm{i}}^{\prime} \mathrm{A}_{\mathrm{ISS}}+\mathrm{J}_{\mathrm{i}}{ }^{\prime} \mathrm{A}_{\text {mast }}\right) / \mathrm{J}_{\mathrm{e}}{ }^{\prime} \mathrm{A}_{\mathrm{SA}}\right] \\
& \text { where }
\end{aligned}
$$

$$
\mathrm{J}_{\mathrm{e}}^{\prime}=9.03 \times 10^{-12}\left(\mathrm{~V}_{\text {avg }} \mathrm{N}_{\mathrm{e}} \mathrm{T}_{\mathrm{e}}\right)^{1 / 2}
$$

(array electron thermal collection from sheath)

$$
\mathrm{J}_{\mathrm{i}}^{\prime}=\left[1.2 \times 10^{-15}(1+|\mathrm{V}| / 4.89) \mathrm{N}_{\mathrm{e}} / 2\right]
$$

(focused ion collection onto structure)

$$
\mathrm{J}_{\mathrm{i}}^{\prime \prime}=\left[1.2 \times 10^{-15}(1+|\mathrm{V}| / 4.89)^{1 / 2} \mathrm{~N}_{\mathrm{e}} / 2\right]
$$

(focused ion collection onto array masts)

and $\mathrm{A}_{\mathrm{ISS}}=20 \mathrm{~m}^{2}, \mathrm{~A}_{\mathrm{mast}}=7.5 \mathrm{~m}^{2}$, and $\mathrm{A}_{\mathrm{SA}}=6.3 \mathrm{~m}^{2}$.

$$
\begin{array}{ll}
\ln \phi=5.194-0.02415 \sqrt{ }\left[\left(\mathrm{N}_{\mathrm{e}} / \mathrm{T}_{\mathrm{e}}\right)^{1 / 2}\right] & (2 \text { arrays }) \\
\ln \phi^{\prime}=5.2147-0.01741 \sqrt{ }\left[\left(\mathrm{N}_{\mathrm{e}} / \mathrm{T}_{\mathrm{e}}\right)^{1 / 2}\right] & (4 \text { arrays })
\end{array}
$$




\section{Fitting the Difference of Two Exponentials}

$\mathrm{V}_{\mathrm{obs}}=-\phi\left[\mathrm{e}^{-\mathrm{at}}-\mathrm{e}^{-\mathrm{bt}}\right]$, because both electron and ion collection decay with time because of surface charging.

$\mathrm{t}_{\mathrm{pk}}=(\ln \mathrm{a}-\ln \mathrm{b}) /(\mathrm{a}-\mathrm{b})$.

- Values of "a" from our fits ranged from 0.43 to $5.5 \mathrm{~s}^{-1}$, (for 1/e times of 0.18 to 2.3 seconds) with a mean of 1.61 and median of $1.24 \mathrm{~s}^{-1}$ (o.62 and 0.80 seconds, respectively).

- Values of "b" from our model fits ranged from 0.056 to o.6o s-1 (for $1 / \mathrm{e}$ times of 1.7 to 18 seconds), with a mean of 0.21 and median of $0.18 \mathrm{~s}-1$ ( 4.8 and 5.6 seconds, respectively).

- Values of the ratio of a/b ranged from 2.40 to 52.7 , with a mean of 10.6 and median of 6.3 .

- Finally, the amplitude $\phi_{\text {fit }}$ ranged from 7.35 to 91.9 volts, with a mean of 28.7 and median of 23.2 . 


\section{RCE fit by the difference between two exponentials}

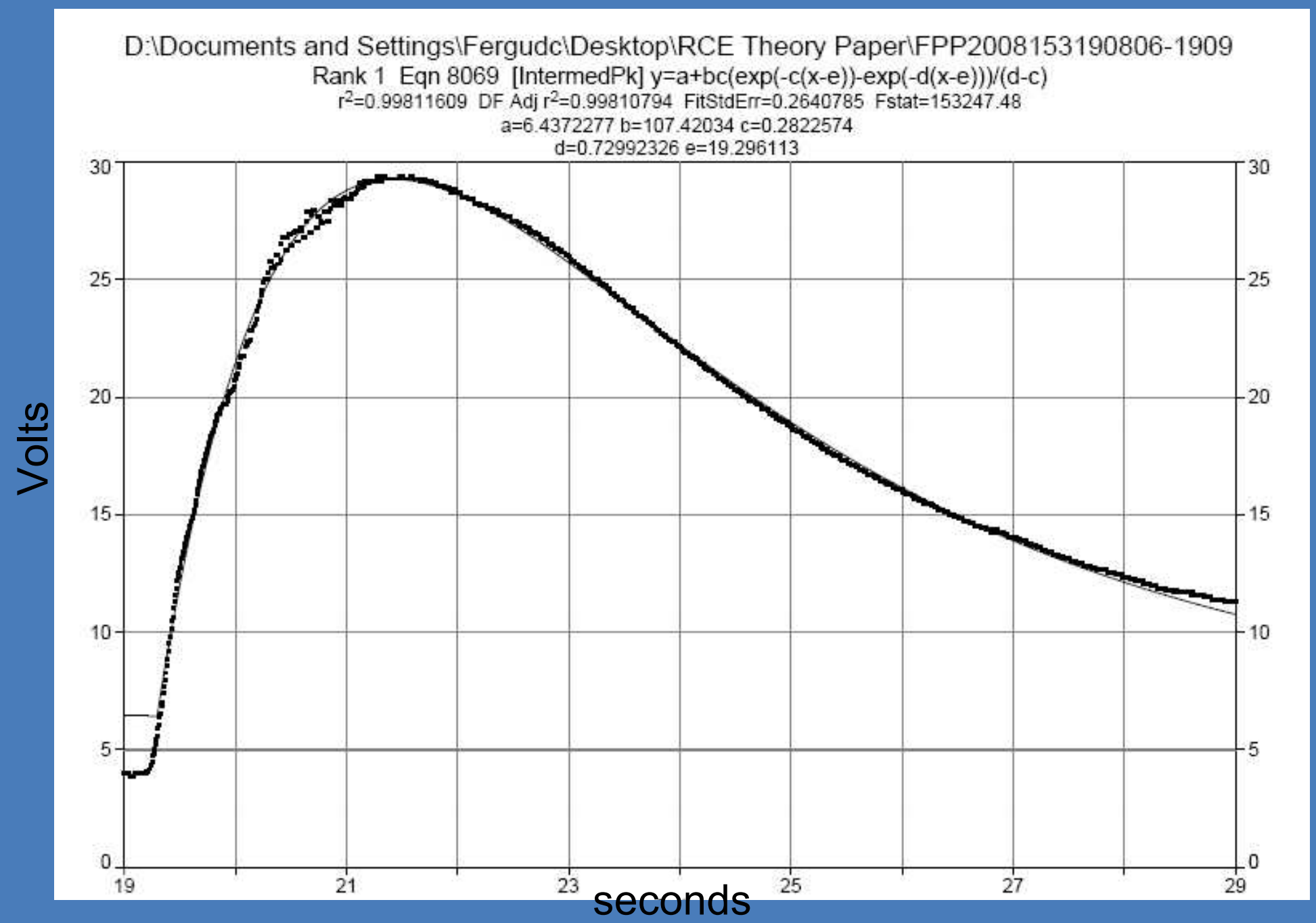


Ist exponential time constant

a $\left(s^{-1}\right)$ vs Ne (ram ion charging on structure elements)

$a\left(s^{-1}\right)$ vs Ne

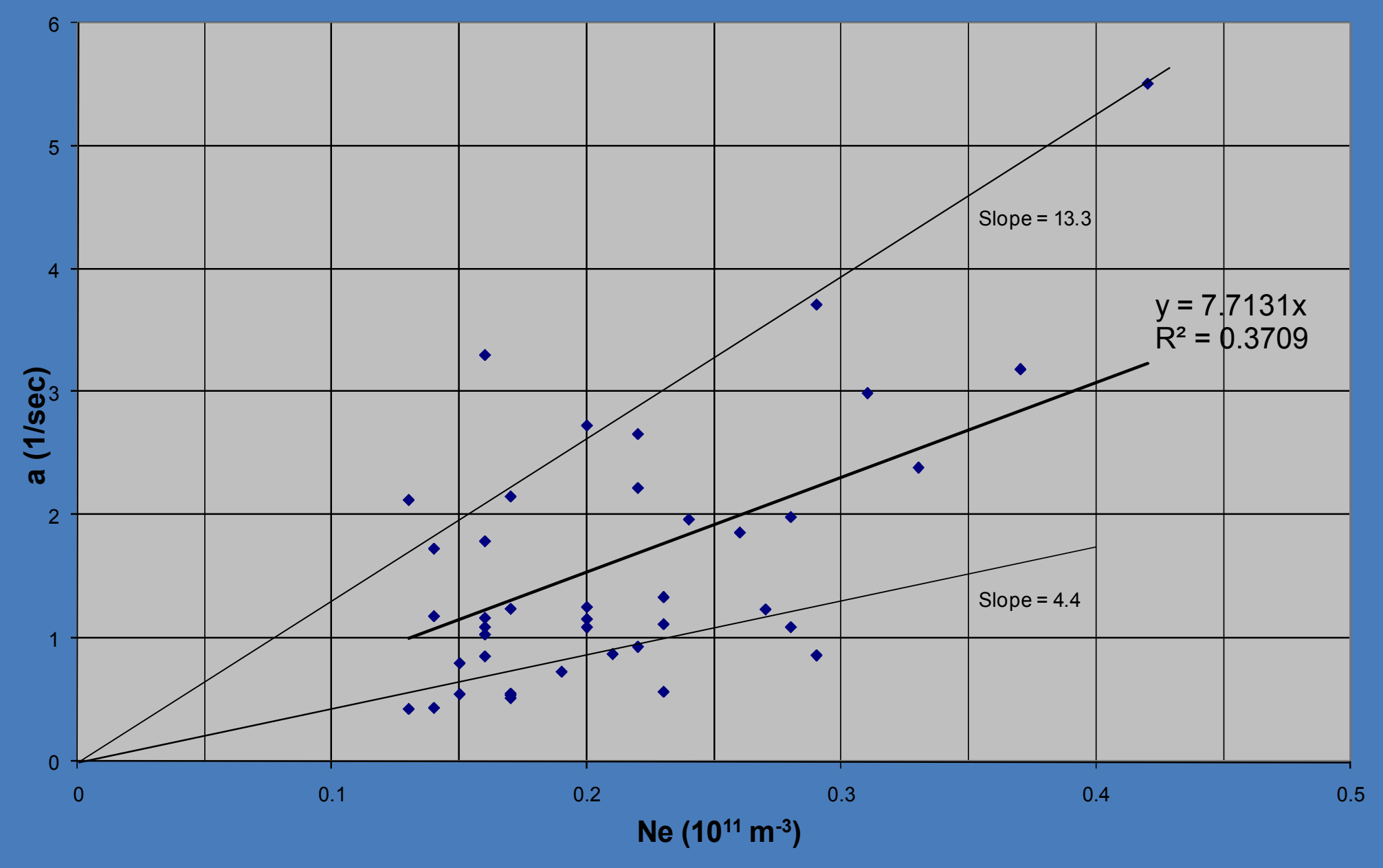


b (s-1) vs $\sqrt{ }\left(\mathrm{Ne}^{\star} \mathrm{Te}\right)$

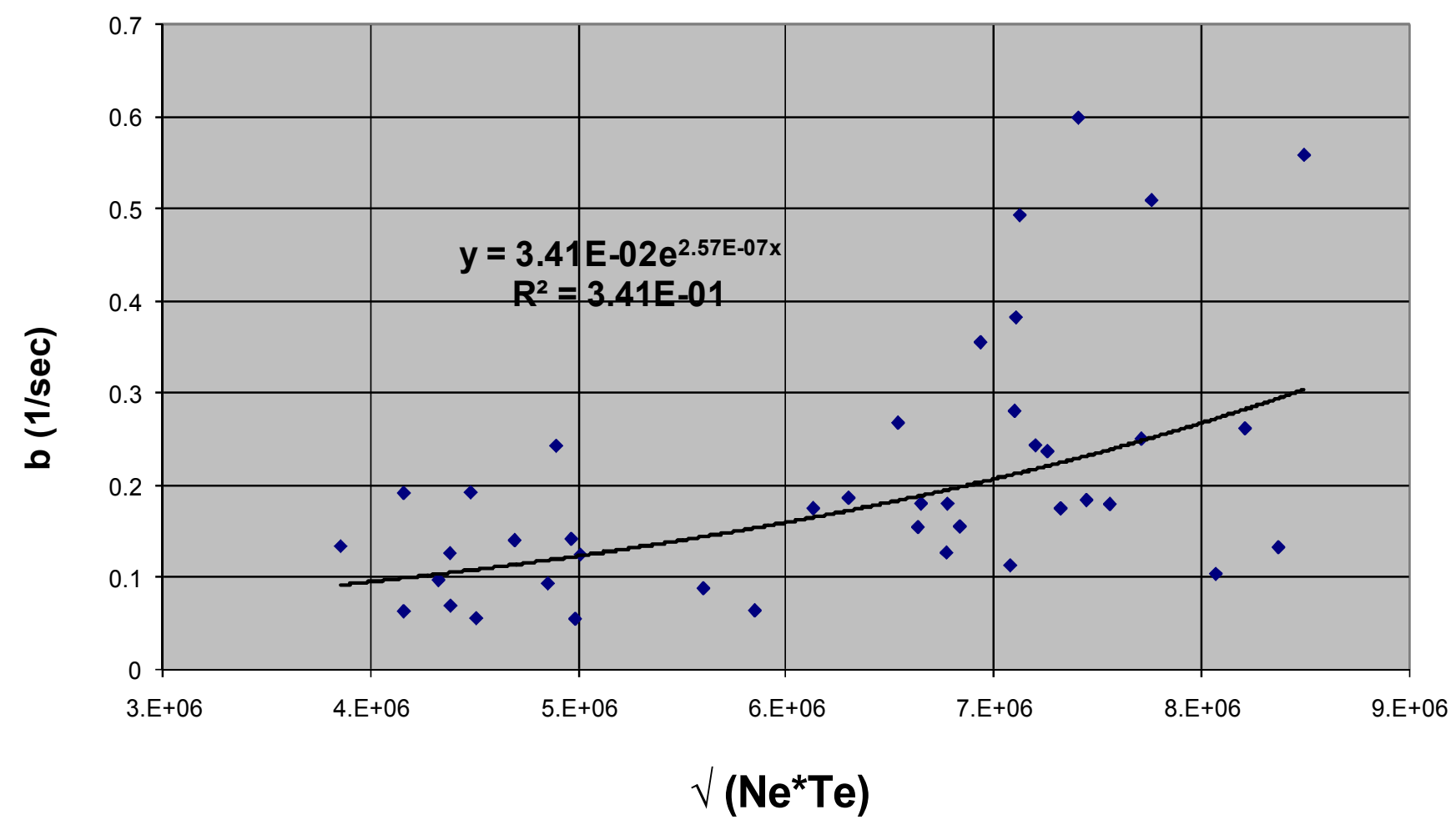




\section{$\varphi$ vs $\sqrt{ }(\mathrm{Ne} / \mathrm{Te})$}

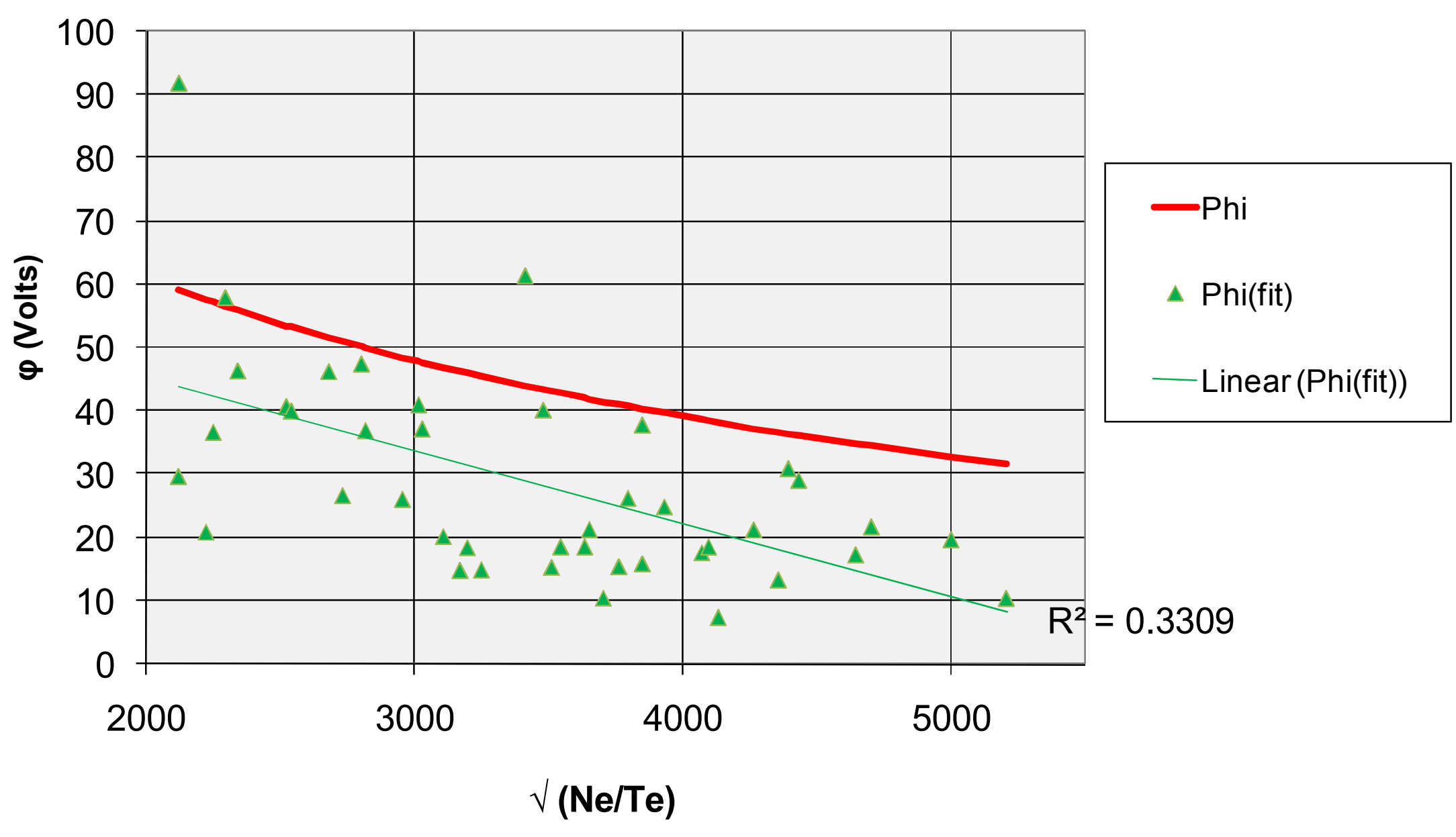


Arormalized Amplitude versus ATrTy Ram Angle (line $=$ cosine law)

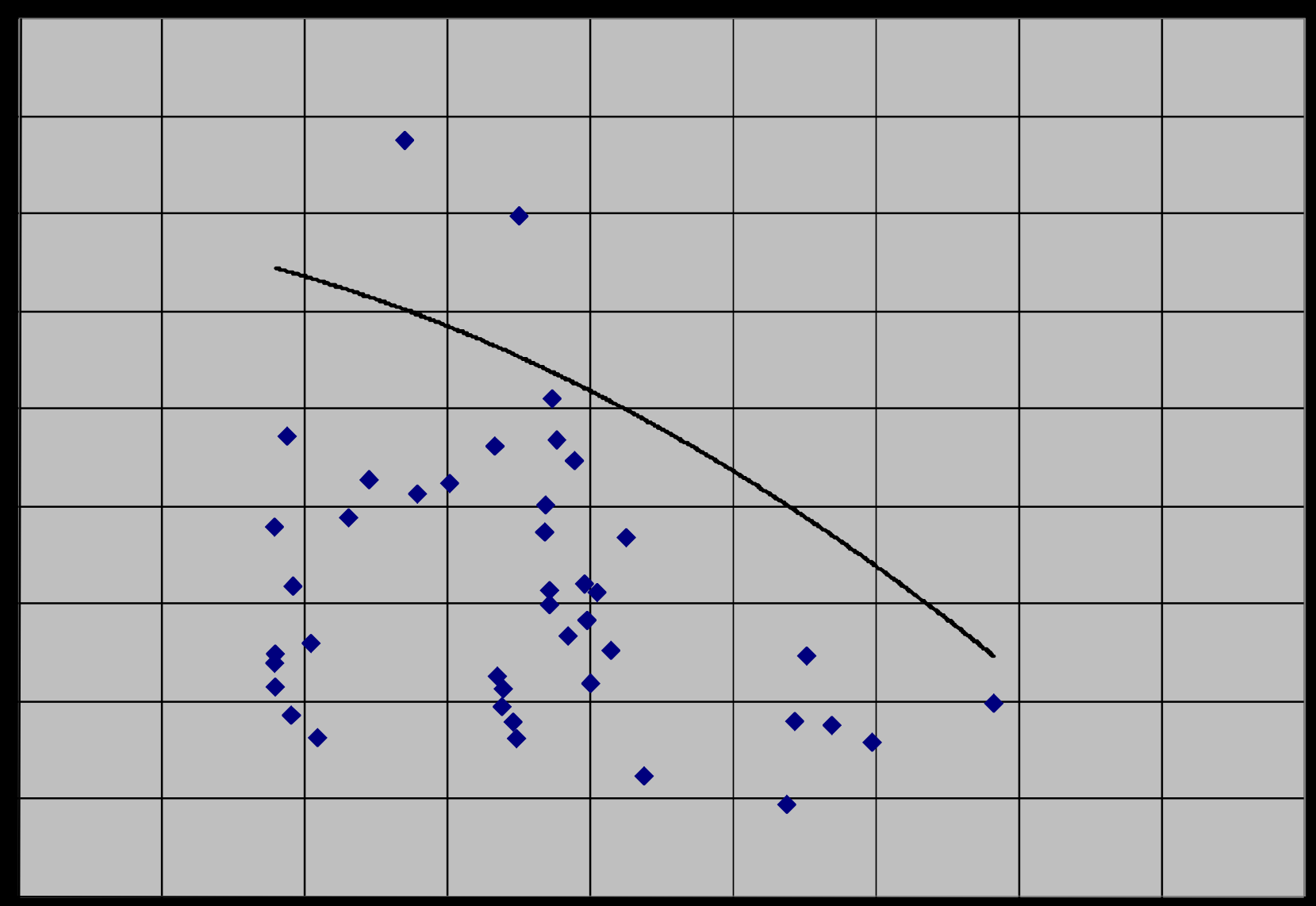




\section{4 active arrays}

$\varphi$ vs $\sqrt{ }(\mathrm{Ne} / \mathrm{Te})$

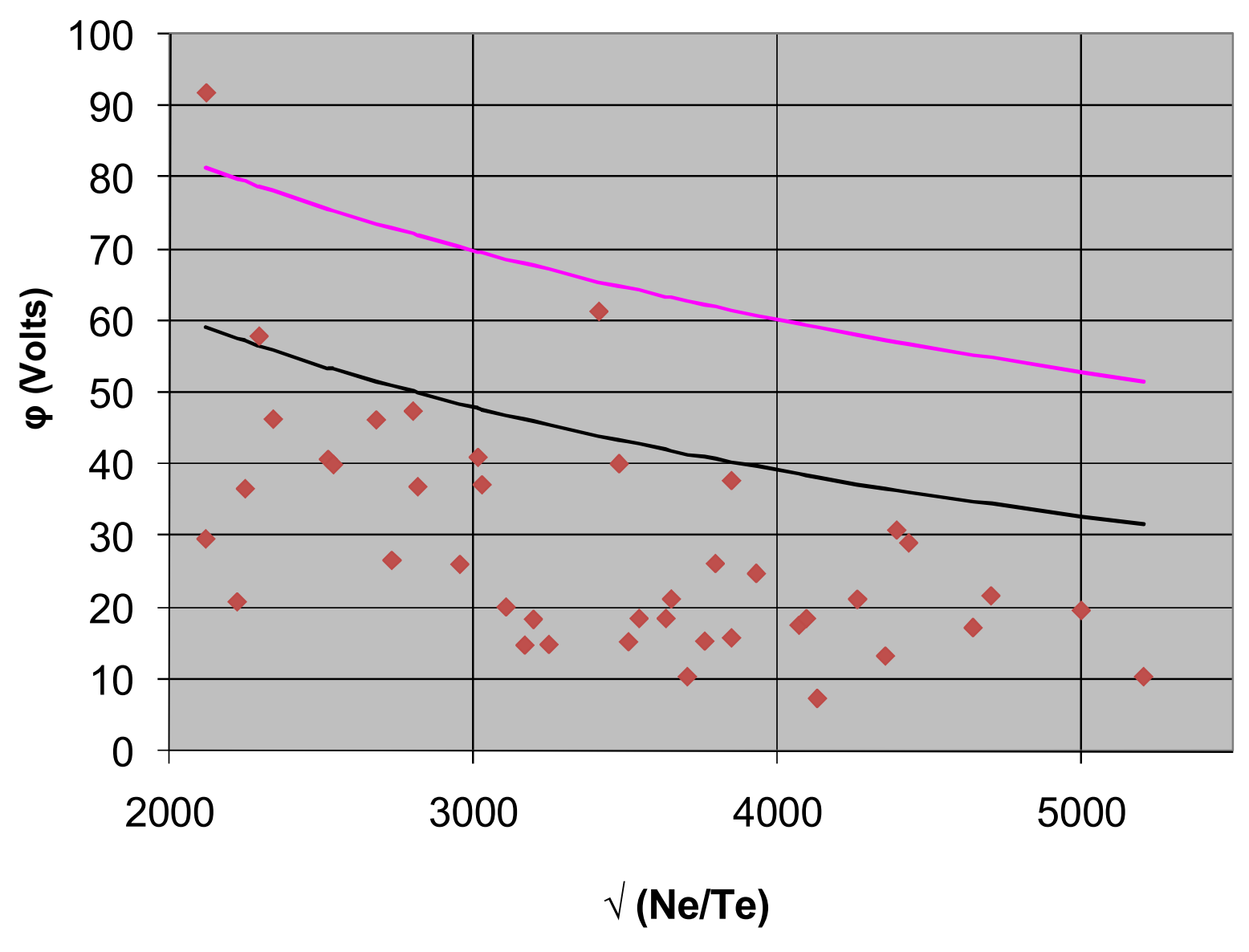

- Phi (fit)

-Phi' 4 arrays

—Phi 2 arrays 


\section{Assembly Complete}

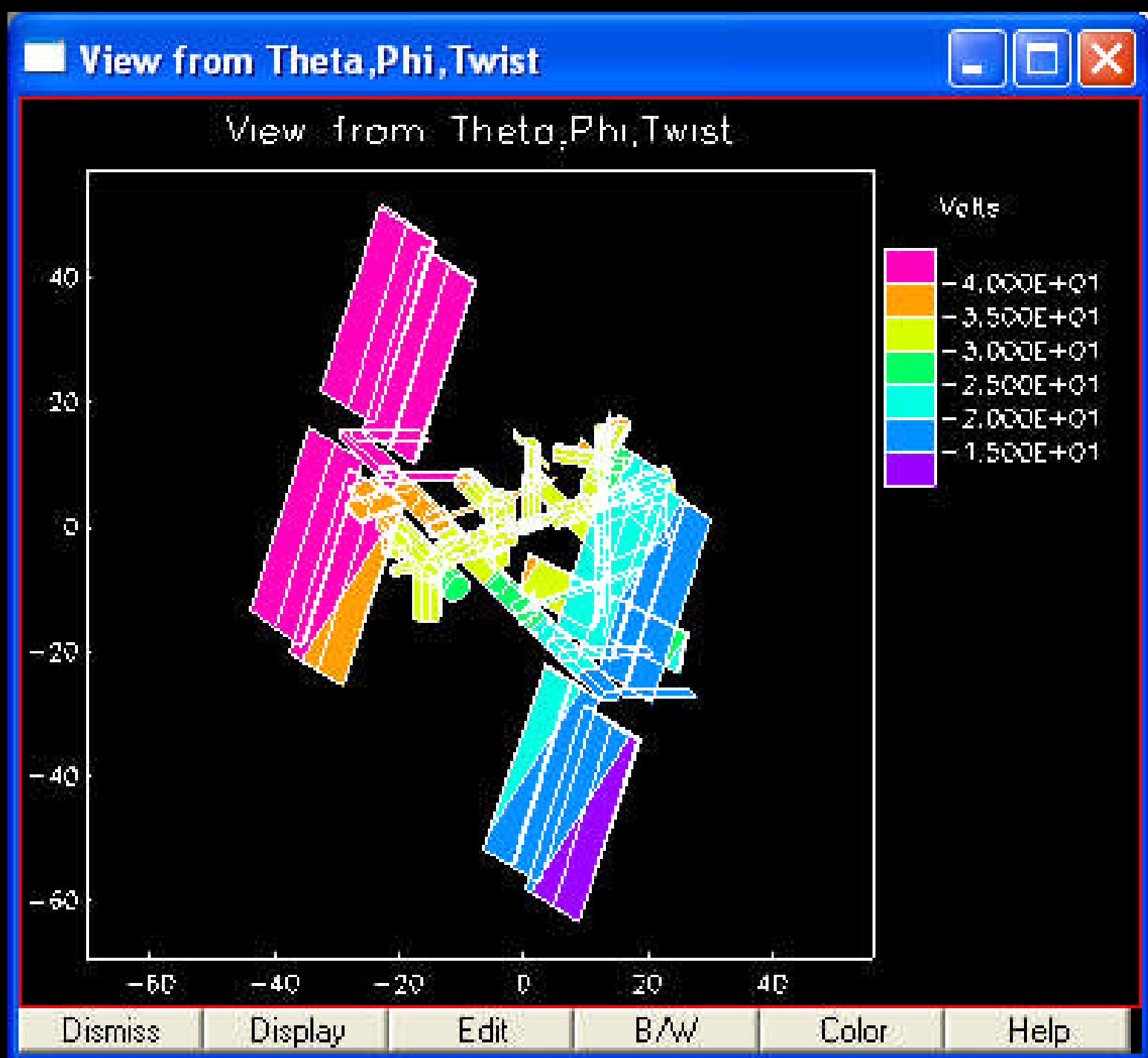




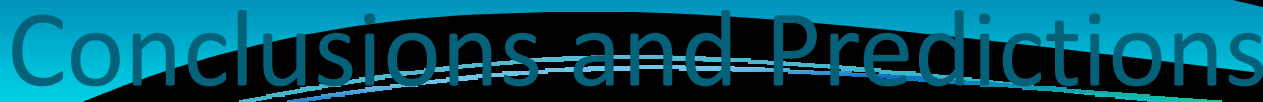


